NBER WORKING PAPER SERIES

\title{
THE SCHOOL-ENTRY-AGE RULE AFFECTS REDSHIRTING PATTERNS AND RESULTING DISPARITIES IN ACHIEVEMENT
}

\author{
Philip J. Cook \\ Songman Kang \\ Working Paper 24492 \\ http://www.nber.org/papers/w24492 \\ NATIONAL BUREAU OF ECONOMIC RESEARCH \\ 1050 Massachusetts Avenue \\ Cambridge, MA 02138 \\ April 2018
}

The authors especially thank Ken Dodge and Sean Reardon for comments on an earlier draft. The data were provided by the North Carolina Education Data Center of Duke University's Center for Child and Family Policy. The views expressed herein are those of the authors and do not necessarily reflect the views of the National Bureau of Economic Research.

NBER working papers are circulated for discussion and comment purposes. They have not been peer-reviewed or been subject to the review by the NBER Board of Directors that accompanies official NBER publications.

(C) 2018 by Philip J. Cook and Songman Kang. All rights reserved. Short sections of text, not to exceed two paragraphs, may be quoted without explicit permission provided that full credit, including $(\odot$ notice, is given to the source. 
The School-Entry-Age Rule Affects Redshirting Patterns and Resulting Disparities in Achievement Philip J. Cook and Songman Kang

NBER Working Paper No. 24492

April 2018

JEL No. I21,I24

\begin{abstract}
$\underline{\text { ABSTRACT }}$
Since, other things equal, older children do better in school, the extent and pattern of delayed entry affects observed patterns in academic performance. This paper provides three new sets of relevant findings, utilizing comprehensive data on birth cohorts of children who enrolled in first grade in North Carolina public schools.: (1) Delayed entry (redshirting) reduces the male-female achievement gap by 11\%; (2) For each of 6 groups defined by sex and race/ethnicity, the likelihood of redshirting is strongly inversely related to academic ability; and (3) A recent shift in the cut date to earlier in the calendar year reduced redshirting, and provided clear evidence that parental decisions are tied to the absolute age of the child rather than age relative to classmates. The adaptation of redshirting to changes in the cut date is an important mechanism by which such changes affect patterns in academic outcomes.
\end{abstract}

Philip J. Cook

Sanford School of Public Policy

Duke University

215 Sanford Building

Durham, NC 27708-0245

and NBER

pcook@duke.edu

Songman Kang

College of Economics and Finance

Hanyang University

222 Wangsimni-ro, Seongdong-gu

Korea

songman.kang@gmail.com

sk92@duke.edu. 


\section{Introduction}

State mandatory attendance laws require children to attend school over a specified age range, while also specifying the minimum age at which children may enroll in public school. For example, in North Carolina, children are required to be at least five years old before enrolling in a public kindergarten; children who turn five after August 31 are required to wait until the following year before enrolling. Parents are allowed to delay their child’s entry, as long as the child is enrolled by age seven. A recent literature has adopted the term "redshirting” for parents' decision to delay their child's entry into first grade (Deming and Dynarski 2008), importing the term from college sports. ${ }^{1}$ Bassok and Reardon (2013) offer two estimates for the nationwide prevalence of redshirting, $4 \%$ and $5.5 \%$, based on different data sets. It is also possible, due to loopholes in the minimum age laws, that some parents enroll their child a year early, which by analogy has been dubbed "greenshirting," but that involves less than one percent of public school children (Bassok and Reardon 2013).

The public interest in noncompliance with the minimum age rules stems from the wellestablished fact that other things equal, being older conveys an academic advantage, at least in elementary and middle school (Bedard and Dhuey 2006; Elder and Lubotsky 2009; Dobkin and Ferrerira 2010; Bassok and Reardon 2013; Cook and Kang, 2016; Cascio and Schanzenbach 2016; Dhuey et al. 2017). For children who comply with the minimum age laws there is a oneyear spectrum of birthdays in each grade. The older children, born just after the cut date, tend to perform better than their younger classmates, as measured by standardized test scores, likelihood of on-time promotion, and the likelihood of being identified with a learning disability (Dhuey and Lipscomb 2010; Elder 2010). Causal analysis of the effect of exact age on academic performance, using regression discontinuity or IV methods, provides a consensus on these beneficial effects, although with some disagreement about whether the effects are attenuated by middle school (Bedard and Dhuey 2006; Elder and Lubotsky 2009; Cascio and Schanzenbach 2016; Cook and Kang 2016; Dhuey et al. 2017). There is every reason to believe that redshirting

\footnotetext{
${ }^{1}$ In intercollegiate college sports, "redshirting” is used as an informal term for the practice of keeping young athletes out of competition for a year to allow them to mature physically without losing a year of NCAA eligibility.
} 
(which tends in practice to be concentrated among children born just before the cut date) would convey the same “old for grade” benefits.

Thus the extent and pattern of noncompliance with the minimum age rule affects levels and patterns in academic outcomes. In recent studies from state and national data sets, there is consensus that redshirting is much more common for males than females, and more common for whites than blacks or Hispanics. Several studies report that the likelihood of redshirting increases with socioeconomic status (SES) (Bassok and Reardon 2013; Dhuey et al. 2017), although Dhuey and her colleagues find a countervailing pattern in Florida of retention in the primary grades that has the effect of eliminating the correlation of age with SES by third grade. Another dimension of interest is whether the decision to redshirt is influenced by the academic preparation or ability of the child prior to enrollment. Two recent studies find a weak positive relationship (Bassok and Reardon 2013) and null relationship (Dhuey et al. 2017).

This paper explores the patterns in on-time enrollment and the deviations therefrom, to better understand what might be motivating parents and to determine the effects of "noncompliance" on patterns in standardized test scores. We analyze a large administrative data set for a birth cohort of children who enrolled in first grade in a North Carolina public school, finding that 92.5\% were “on time” relative to the state regulation, while the others were either early (0.8\%) or late (6.7\%). As expected, white males were greatly overrepresented in the late (redshirt) group. We estimate the causal effect of age on the standardized end-of-grade test in third grade (EOG3) using months of birth as instruments: an extra year of age raises scores by .36 of a SD in reading, and .30 in math, and these estimated effects are quite similar across race-sex groups. These estimates are used to assess the overall effects of redshirting on average EOG3 scores for six groups defined by sex and race/ethnicity, finding, for example, that every group's averages are raised by redshirting, but that white males enjoy the biggest boost given a redshirting rate of $9.9 \% .^{2}$

\footnotetext{
${ }^{2}$ The focus on third-grade outcomes is dictated by the limitations of the dataset. The positive effects of being old for grade extend through middle school and beyond, including not only standardized test scores but also the likelihood of an exceptionality designation and involvement in criminal activity before age 16 (Cook and Kang 2016; Dhuey et al. 2017). And despite this persistent advantage, old-for-grade youths are more likely to drop out before graduation (Dobkin and Ferreira 2010; Cook and Kang 2016) and then turn to serious crime (Cook and Kang 2016).
} 
This approach allows us to assess the effects of redshirting on the usual test-score gaps by sex (girls outperform boys) (Autor et al. 2016) and race and ethnicity (whites outperform blacks and Hispanics) (Clotfelter, Ladd and Vigdor 2009). The largest effect is for the white female-male gap in reading, which would be $11 \%$ larger if it were not for the fact that white boys are twice as likely to redshirt as white girls. On the other hand, the male black-white test score gap is increased by differential redshirting (albeit just 1\%).

To better understand parents' choices about redshirting, we propose and implement a method to take account of academic ability, using hypothetical EOG3 scores (adjusted for delay) as a proxy for academic ability at the time the redshirting decision is made. Contrary to other recent reports, we find a strong negative effect of academic ability on the likelihood of redshirting, an effect that is present for all six demographic groups. (The effect of household poverty is to increase redshirting, but that effect is reversed in sign if academic ability is included as a covariate.) This pattern has the effect, then, of differentially raising the observed EOG3 scores for children of lower ability.

Given that redshirting patterns have noteworthy effects on the gender gap and average performance of less able children, changes in public policy that affect the prevalence of redshirting are of public concern. In particular, North Carolina recently changed its legislated cut date for school entry from October 17 to September 1, a change that would be expected to affect the prevalence of redshirting if parents' to the extent that parents' judgments about whether to delay a child’s entry are influenced by absolute age (maturity, preparation), rather than by age relative to potential classmates. We analyze redshirting patterns before and after this change, with a clear finding: while the prevalence of redshirting drops to near zero following the change in cut date, prevalence during July and August is unchanged. It appears, then, that it is absolute-age-related considerations that influence parents' decisions, and hence that the prevalence of delayed entry is directly influenced by a state's choice of cut date. That consequence, intended or not, deserves consideration in making the choice of cut date.

Dobkin and Ferreira (2010) report that later earnings are unaffected by relative age in school, which they interpret as the net result of the positive and negative effects of being old for grade. 
In what follows we begin with a brief discussion of the parents' decision whether to delay their child's entry into kindergarten. The next three sections describe the data, report the results of analyses of the effect of exact age on school achievement, and then provide estimates of how observed redshirting patterns affect test-score gaps by sex and race. We then turn to a novel assessment of the influence of academic ability on the redshirting decision, followed by a report of results of a natural experiment that strongly suggests that parents are influenced by the calendar age rather than the relative age of their child in school. A final section concludes.

\section{The parents' choice to postpone their child's school entry}

Here we sketch the considerations that may be relevant to parents who are considering delaying a year before enrolling a child in public kindergarten. Their sense of the child's maturity (school readiness) and academic ability, possibly informed by consultation with a teacher or other professional, may influence the parents' decision. An extra year would yield a greater chance for academic and social success. (For some parents, increasing the child's likelihood of success in school athletics may also be of interest.) The fact that boys are more likely to delay entry than girls is one well-established pattern compatible with a parental concern with the child's maturity (DiPrete and Jennings 2011). But delayed entry comes at the cost of delayed graduation from high school (if the child progresses on the normal schedule through school), or a greater chance of dropout before graduation (Cook and Kang 2016; Angrist and Krueger 1991). Delayed entry may also be costly to the household if it requires additional child care or paid nursery school. Even if free public pre-school is available and attractive to the parents, the hours and transportation arrangement may be less desirable than kindergarten.

Government policy may influence the prevalence of delayed entry. For example, a program that subsidizes child care may make delayed entry more attractive, while state-supported pre-school programming may reduce it. ${ }^{3}$ Here we focus on the potential for another policy domain, the

\footnotetext{
${ }^{3}$ North Carolina has two state-wide programs to improve services and school preparation from pre-school children. The Smart Start program provides funding to improve childcare services at the county level for all children between the ages of 0 and 5. More at Four (now NC PreK) provides funding for pre-school for disadvantaged 4-year-olds. Both programs have been shown to be effective in improving educational outcomes through at least grade 5 (Dodge et al. 2016). Possible effects on the redshirting decision have not been established.
} 
state's cut date, to influence redshirting patterns. Whether the choice of date matters depends on whether the parents' decision is more influenced by the child's absolute (calendar) age, or age relative to potential classmates. For example, if the parents' main goal is for the child to someday make the high school basketball team, then age and maturity relative to classmates is what matters, and the cut date would be irrelevant - there would always be the same incentive to delay entry. If the primary goal is for the child to make normal progress in primary school, then an absolute judgment of maturity (school readiness) may be the dominant concern.

In particular, North Carolina attendance law was amended to change the cut date from October $17^{\text {th }}$ to September $1^{\text {st }}$ beginning with the 2004 birth cohort. One consequence was that on-time students born in August became younger relative to their class following the change, though of course their absolute age did not change. To the extent that parents are concerned about their child's age relative to classmates, then we would expect an increase in redshirting for August births following this reform, a prediction we test in what follows.

\section{Data Description}

Under current law in North Carolina, a child must reach the age of 5 on or before August 31 to be eligible to enter a public kindergarten that year (NC G.S. 115c-364). ${ }^{4}$ Some children delay kindergarten entry by a year or two, skip kindergarten, or spend more than a year in kindergarten before entering first grade, but this minimum age requirement for kindergarten entry largely determines the age distribution in North Carolina classrooms. Most children born just before the cut date, and nearly all children born after, begin school as soon as legally permitted, with the result that there is a sharp discontinuity in age between first graders born in August versus those born in September.

In order to examine the relationship between date of birth and school entry, and subsequent schooling outcomes, we use student-level administrative data from the North Carolina public school system, provided by the North Carolina Education Research Data Center (NCERDC). The

\footnotetext{
${ }^{4}$ The legal age requirement for public school entry (NC G.S. 115c-364) allows for two exceptions: children born after the cutoff date are still eligible to enter kindergarten if 1) they have been attending school in a different state in accordance of the laws of that state before moving to North Carolina or 2) principals find them mature enough to enter school. As seen in Table 4, this academic "greenshirting" is very rare in practice; the share of first graders below age six is less than $1 \%$.
} 
data contain detailed information on demographic characteristics and schooling experiences of students attending North Carolina public schools, including their gender, race/ethnicity, month and year of birth, school attended, economic disadvantage (measured by their eligibility for free or reduced price lunch), exceptionality status, and academic performance on end-of-grade (EOG) reading and math tests. (EOGs are standardized achievement tests administered statewide for students in grades 3 through 8.) For this analysis, we focus on the exceptionality status and EOG reading and math test scores in grade 3 (standard normalized at the test year-by-subject level) as measures of students' early academic outcomes.

Our main sample consists of children born between November 2003 and August 2004, who later attended a North Carolina public school between grades 1 and 3. Had everyone complied with the minimum age and entered first grade in the year they turned 6, all of our sample students would have entered first grade in fall of 2010. ${ }^{5}$ Furthermore, we can express school starting age among compliers as a simple linear function of their month of birth. For example, children born in November 2003 would be $6 \frac{10}{12}$ years old and those born in August 2004 would be $6 \frac{1}{12}$ years old when starting first grade in September 2010. ${ }^{6}$ In reality, however, children's month of birth and their timing of school entry are not perfectly correlated because of academic redshirting and (to a lesser extent) grade retention in kindergarten.

We begin our analysis on the effects of school starting age and academic redshirting on schooling outcomes by graphically illustrating the relationship between students' month of birth, school starting age, and several early schooling outcomes. Figure 1 plots students' starting age if they comply (line) and actual average school starting age (dots) against their month of birth. Most students born in the fall comply with the minimum age requirement, as the actual and predicted school starting age are closely aligned. The share of children entering first grade older than expected noticeably increases in later months.

\footnotetext{
${ }^{5}$ Until 2008, the school entry cutoff date in North Carolina was October 16. Children born between September 1st and October 16th, 2003 were thus eligible to enter school one year earlier than our sample students.

${ }^{6}$ School year in North Carolina begins in late August or early September. The legal requirement is that the opening date for school year cannot be earlier than the Monday closest to August 26 (NC G.S. 115C-84.2).
} 


\section{[Figure 1]}

Figure 2 shows that the rate of delayed school entry varies by birth month. It is evident that delayed school entry (either due to academic redshirting or grade retention) is heavily concentrated among those born just before the cutoff date. Less than 5 percent of children born between November and March enter first grade older than expected, but that rate is more than 11\% among July births and 15\% among August births.

\section{[Figure 2]}

Figure 3 plots students' average EOG3 reading and math scores by birth month. Children who enter school older (because they were born in earlier months) also perform better on reading and math achievement tests. Furthermore, the relationship between test scores and birth months is nearly linear for both reading and math scores. A recent study finds that children born in winter months tend to come from households with greater disadvantage relative to those born in summer months (Buckles and Hungerman 2013), but that does not appear to be the case in the North Carolina data.

\section{[Figure 3]}

Figures 4, 5, and 6 illustrate the shares of students diagnosed as learning disabled (Figure 4), or speech impaired (Figure 5), or identified as academically and intellectually gifted (Figure 6) in grade 3 by birth month. While the relationship is more noisy than the relationship between months of birth and test scores (Figure 3), the figures show that children who were born in earlier months and entered school older are less likely to be diagnosed as disabled and more likely to be considered as academically gifted, compared to their classmates born in later months.

\section{[Figure 4]}

\section{[Figure 5]}

\section{[Figure 6]}

Table 1 presents summary statistics on various characteristics of the sample. With respect to race and ethnicity, it is 52\% white, 25\% black, and 15\% Hispanic students, with $8 \%$ other. Based on their free or reduced price lunch eligibility in grade 3, 56\% are low income. The average age at entry to first grade is 6.5 ; $92 \%$ of students enter first grade in the year predicted by their month 
of birth, while $7 \%$ enter school older than expected. When they reach third grade, 5.4\% are diagnosed as having learning disability, $4.9 \%$ a speech impairment, and $9.1 \%$ are considered academically and intellectually gifted (AIG).

[Table 1]

\section{Effect of age on academic outcomes}

If every child entered school in the first year they became eligible, it would be straightforward to estimate the reduced-form effect of school starting age on schooling outcomes. Assuming that month of birth is uncorrelated with other unmeasured determinants of outcomes, a regression on observed school starting age (SSA) would provide unbiased estimates: ${ }^{7}$

$$
Y_{i}=\alpha+\beta X_{i}+\gamma S S A_{i}+\epsilon_{i}
$$

where $Y_{i}$ is the outcome of interest, $X_{i}$ is a vector of individual covariates, and $S S A_{i}$ is the school starting age of student i. In reality, however, school starting age is to some extent endogenous, and both the schooling outcome and school starting age are likely to be correlated with unobserved characteristics of student i; among other considerations parents may delay sending their children to school if they do not appear as mature and school-ready as their potential classmates. Unless researchers control for children's level of maturity and school-readiness in Equation (1), school starting age $\left(S S A_{i}\right)$ is likely to be correlated with the error term $\left(\epsilon_{i}\right)$, and the OLS coefficient $\gamma$ will be a biased estimator of the causal effect of school starting age.

Following the previous literature, we run an IV estimation to address this endogeneity problem. In the first-stage estimation, students' months of birth are used as instruments for their school starting age:

$$
S S A_{i}=\zeta+\eta X_{i}+\sum_{m=1}^{10} \theta_{m} d_{i m}+\iota_{i}
$$

\footnotetext{
${ }^{7}$ Even with the perfect compliance with the age requirement for school entry, this reduced-form estimation cannot separate the effect of relative maturity (i.e., entering school older than other students) from the effect of absolute maturity (i.e., entering school older in an absolute sense). Several recent studies, however, attempt to separately estimate the effects of relative and absolute maturity on students' academic achievement (e.g., Elder and Lubotsky 2009; Carlsson et al. 2015; Cascio and Schanzenbach 2016;).
} 
where $S S A_{i}$ represents student i's school starting age, $X_{i}$ the vector of individual characteristics (gender, race/ethnicity, and economic disadvantage), and $d_{i m}$ the month-of-birth indicator which is equal to 1 if student $\mathrm{i}$ was born in month $\mathrm{m}$ and 0 otherwise. The month-of-birth indicators are normalized with respect to the school entry cutoff date so that $\mathrm{m}=1$ if born in November 2003 and $\mathrm{m}=10$ if born in August 2004. $\iota_{i}$ is an idiosyncratic error.

Using the predicted school starting age from the first-stage, the second-stage equation is:

$$
Y_{i}=\kappa+\lambda X_{i}+\mu \widehat{S S A_{l}}+v_{i}
$$

where $Y_{i}$ represents the outcome of interest and $\widehat{S S A_{\iota}}$ is student i's predicted school starting age from the first stage. $\mu$ can then be interpreted as the local average treatment effect (LATE), i.e., the average treatment effect for the subpopulation of those who complied with the minimum age requirement and entered school in the first year of eligibility (Imbens and Angrist 1994).

Table 2 presents OLS and IV estimates of the effect of school starting age on several early schooling outcomes. The OLS estimates presented in Panel (A) show that school starting age is significantly negatively correlated with EOG3 reading and math scores. Moreover, children who start school older are more likely to be diagnosed as learning disabled and less likely to be considered academically and intellectually gifted in grade 3. As discussed above, however, the endogeneity of school starting age is likely to cause OLS estimates to be biased. For example, if academic redshirting is mostly done by parents whose school-aged children are not mature enough, the OLS estimate for the effect of school starting age on academic achievement will be downward-biased.

The IV estimates presented in Panel (B) tell a qualitatively different story. The month of birth is strongly negatively related to EOG scores. Once self-selection about when to begin school no longer influences the statistical results, a one-year increase in school starting age is associated with significant increases in the EOG3 reading and math achievement scores (0.36 and 0.30 standard deviation increases, respectively). It also significantly decreases the likelihood of being diagnosed as learning disabled (a 1.6 percentage point decrease) and speech impaired (a 1.0 percentage point decrease), and increases the likelihood of being considered academically and intellectually gifted (a 2.3 percentage point increase) in grade 3. The F statistics for the joint significance of excluded instrument variables, reported at the bottom of Table 2, show that use of 
month-of-birth indicators satisfies the conventional weak IV test (Bound, Jaeger, and Baker 1995).

To put these magnitudes in the context of previous studies, Chetty, Friedman, and Rockoff (2014) report that a 1 standard deviation improvement in teacher quality leads to $0.10(0.14)$ standard deviation increases in English (math) test scores, based on test scores and teacher assignment data in grade 3-8 from a large U.S. school district. Dobbie and Fryer (2011) evaluate the effect of attending the Promise Academy in the Harlem Children’s Zone on schooling outcomes, and find that attending the Promise Academy elementary school, a "No-Excuse" charter school, increases students' English and math scores by 0.2 standard deviations per year. Thus the beneficial effect of entering school a few months older on early academic achievement is of a similar magnitude as having an unusually effective teacher or attending a highly effective school.

[Table 2]

The prevalence of redshirting differs widely among groups defined by sex and race or ethnicity, and it is of interest to determine whether the academic effects of redshirting also differ. To explore the potential heterogeneity in the effect of school entering age, IV analyses (Equations 2 and 3) were run separately for each race-by-sex group and report the results in Table $3 .{ }^{8}$ Panel (A) shows the IV estimates obtained from the aggregate sample (from Table 2), and subsequent panels present IV estimates obtained from each race-by-sex group separately. Across all race-bysex groups, we find that the effect of school starting age on early academic achievement is significantly positive. The effect of entering school one year older on EOG 3 reading score ranges from a 0.27 standard deviation increase for black females to 0.43 standard deviation increase for Hispanic females; the same two groups bracket the range for EOG3 math scores (.21 to .38). Figure 7 graphically illustrates the magnitudes of group-specific IV estimates for the effect of school starting age on EOG3 reading and math scores. With a possible exception of black females, the estimated effects for both EOG3 reading and math scores are quite homogeneous.

\footnotetext{
${ }^{8}$ Race and gender indicators are dropped from regression when running the IV regressions for each race-by-gender group.
} 
[Table 3]

[Figure 7]

In addition to the IV analysis presented above, we also ran an analysis comparing academic outcomes of students born in August and September of 2004. Since the school entry cutoff date was August 31, those born in August typically enter school one year earlier than those born in September. This comparison, which exploits the sharp discontinuity in school entry age among similar-aged children, amounts to a regression discontinuity (RD) analysis. Our RD estimates, presented in more detail in Appendix B, are consistent with the IV estimation results shown above; children who enter school older (September births) perform significantly better on EOG 3 reading and math tests, are less likely to have learning disability and speech impairment, and more likely to be considered to be academically and intellectually gifted in grade 3 . These findings closely align with the RD estimates presented in a recent working paper by Dhuey et al. (2017), which compared academic achievement, educational attainment, and juvenile incarceration outcomes of children born just before and after the cutoff date using administrative data from Florida.

\section{Academic Redshirting and Achievement Gaps}

The results above motivate the question to what extent the early achievement gaps across race and sex groups can be explained by the difference in their school entry age. Panel (A) of Table 4 shows the rates of early, on-time, and delayed school entry for each race-by-sex group. We find that early school entry is rare, less than $1 \%$ for all the groups. Delayed school entry is more common and more differentiated across sex and race. Within each racial group considered, female students are more likely to enter school on-time than male students ( $94.5 \%$ vs. 89.5\% for whites, $95.0 \%$ vs. $91.5 \%$ for blacks, and $94.0 \%$ vs. $91.3 \%$ for Hispanics). Among males, Blacks (92.3\%) and Hispanics (92.2\%) are more likely to enter school on time than Whites (90.1\%).

Panel (B) presents students’ average EOG3 reading score (“Actual Mean”), as well as the EOG3 reading score predicted by their birth year ("Hypothetical Mean”). For example, for students who entered first grade one year older than expected by their birthdates, 0.359 (the IV estimate for the effect of entering school a year older) is subtracted from their actual EOG3 reading scores. Similarly, the IV estimate (0.359) is added to the EOG3 reading scores of students who entered 
school a year earlier than expected. Overall, this age-adjustment lowers students' average EOG3 reading score by a 0.016 standard deviation, demonstrating that the overall level of academic achievement among 3rd graders would have been slightly lower in the absence of academic redshirting or greenshirting.

The rates of early and delayed school entry differ across different race and sex groups. Black females have the lowest rate of delayed school entry (4.0\%), and the score-adjustment only leads to a 0.01 standard deviation decrease in the average EOG3 reading score. On the other hand, $9.9 \%$ of white males delay school entry, and adjusting for their age advantage leads to a 0.03 standard deviation decrease in the average EOG3 reading score. The same type of adjustment is made to EOG3 math scores. The results are presented in Panel (C). Again, the magnitude of the age adjustment is the highest among white males whose average EOG3 math score would have been 0.02 standard deviation lower in the absence of redshirting, and the least for black females

whose average score would have been just 0.006 lower. We also performed this score-adjustment by school starting age using group-specific IV estimates from Table 3, and obtained similar results (See Appendix Table A1).

[Table 4]

Table 5 reports how much of the observed racial and gender gaps in EOG3 reading and math scores is driven by differential patterns of academic redshirting and greenshirting. The observed gap in EOG3 reading score between white males and females is 0.151 standard deviation. The gap would have been 0.017 standard deviation (11\%) larger if all children had entered first garde on time. Similarly, adjusting for the early and delayed school entry would have increased the black female-male gap in EOG3 reading scores by 0.012 standard deviation (6\%) and Hispanic female-male gap by 0.009 standard deviation (8\%). We also find that correcting for the different patterns of school entry timing lowers the white-black and white-Hispanic male achievement gaps, but the magnitude of this correction is much smaller (around 1\%).

[Table 5]

\section{Determinants of Delayed School Entry}

It is well documented that delayed school entry is more common among males and whites, but only few studies investigate other correlates of the delay. Dobkin and Ferreira (2010), using 
birth-certificate data from Texas and California, find that minorities and children with less-thancollege-educated parents are more likely to comply with the school entry laws (as opposed to redshirting). Based on data from the kindergarten cohort of the Early Childhood Longitudinal Survey (ECLS-K), Bassok and Reardon (2013) find that redshirting is more common among white, male, and high-SES children.

In this section, we explore determinants of delayed school entry using the sample of North Carolina public school students born between November 2003 and August 2004 (see Section III). The dependent variable in the logit regression analysis is delayed school entry ( 1 if entered first grade older than expected, 0 otherwise). The regressors include indicators for months of birth, race-by-gender group, and economic disadvantage, as well as hypothetical academic achievement in grade 3. The results are reported in Table 6.

[Table 6]

In the baseline specification (first column), only month-of-birth indicators are included as explanatory variables; in this specification and others, the likelihood of delayed school entry is monotonically increasing in the month of birth. In the second column, race-by-sex indicators are included. Compared to white females all three male groups (white, black, and Hispanic) are significantly more likely to delay school entry, and white males are most likely to delay.

In the third and fourth columns, we additionally control for students' economic disadvantage and then the hypothetical performance on EOG3 reading and math achievement tests. To compute the hypothetical reading and math scores in grade 3 , we proceed as before, "correcting” the observed test scores if the student was younger or older. For example, for those who entered school one year older than expected, we compute their predicted EOG3 scores by subtracting our IV estimate of the school starting age effect ( 0.36 for reading and 0.30 for math) from their actual EOG3 reading and math scores. For students who entered school on-time, the predicted EOG3 scores are equal to their actual scores.

The hypothetical academic performance in grade 3 is a strong and significant predictor of delayed school entry. A reasonable interpretation is that parents are more likely to delay sending their children to school if they expect their children's academic performance to be weak if they begin school on time. 
Interestingly, the inclusion of academic ability as explanatory variables leads to a qualitative change in the effect of economic disadvantage (from positive to negative) and in the estimated effects for the two groups of minority males (also from positive to negative).

To further explore the differences between race-sex groups in the correlates of redshirting, we reran the logit analysis with a full set of covariates for each of the race-sex groups separately, thus allowing for a full set of interactions between demographic group and all other covariates. The results are reported in Table 7. Month of birth has the strongest effect for whites (both male and female). Economic disadvantage is associated with reduced redshirting for white and Hispanic males, but increased redshirting for black males; the effect on females is negligible. Of greatest interest is that the decision to redshirt is highly sensitive to academic ability (hypothetical EOG3 reading scores especially) for all of the race-sex groups. The effect for the reading score is quite homogeneous across five of the six groups, the exception being white males.

[Table 7]

The discovery that academic ability has an important effect on the decision to delay entry suggests that within each race-sex group, redshirting tends to disproportionately benefit weaker students.

\section{The effect on redshirting of a change in the cut date}

The analysis so far shows that students' age and academic ability are important determinants of delayed school entry. Parents' judgments about whether their child is ready to start school could be made relative to some absolute standard of school readiness, or influenced by a comparison with the reference groups of potential classmates, as discussed in Section II. The distinction becomes relevant in predicting the effect of a change in the state's cut date. North Carolina recently did change the minimum age for school entry, providing clear evidence that the absolute judgment is dominant.

Until 2008, North Carolina law specified that children had to be at least 5 years old before October 17 to be eligible to enter a public kindergarten that year. Thus, children born in September and early October were among the youngest students in class if they entered on time, and it was common for that group to delay entry to the following year and begin school older than most of their classmates. In 2009, however, the cutoff date was shifted to September 1, and 
thereafter children born in September and October were all required to wait an extra year to enter kindergarten, making them older than most of their classmates without redshirting. On the other hand, under the new regime, children born in July and August who entered on time became the youngest children in the classroom.

This cutoff change creates a unique natural experiment to gauge the role of students' absolute and relative age in the parents' school entry timing decision. If the decision to delay school entry is mainly driven by students' absolute age, the rate of redshirting among July and August births would remain unchanged after the change in cut date; regardless of the cut date change, they will start kindergarten at the same biological age, i.e., just after turning five. However, if students' relative age is the main determinant of redshirting, the cut date change should increase the rate of redshirting among August births; more parents would delay sending their child to school so that the child would not be the youngest in his classroom. If relative age were all that mattered, then the redshirting pattern in August would mimic the previous redshirting pattern in the four weeks prior to October $16^{\text {th }}$.

For this analysis, data were obtained from the NCERDC on the exact dates of birth for students who 1) were born between July and December in 2003 and 2004 and 2) attended a North Carolina public school for first grade. Figure 8 shows the 5-day averages of the rate of delayed school entry for the two cohorts. The two vertical bars represent the new cutoff date, September 1 (day -47), and old cutoff date, October 17 (day 0).

Consider the 2003 cohort first, who were subject to the old cutoff date. Children born before October 17, 2003 were eligible to enter school a year earlier than those born after October 17, 2003, but a large number of children born just before the cut date delayed their school entry; the 5-day average rate of delayed school entry was more than 20 percent at the end of August and reached nearly 40 percent just before the cutoff date. By contrast, among the 2004 cohort, the rate of delayed school entry for children born between September 1 and October 16 was close to zero, which is not surprising. What is noteworthy, however, is that the rate of delayed school entry among July and August births remained essentially unchanged, even though their relative age in the school cohort had changed significantly. If on time they were now the youngest in their classroom, but there is no evidence that their rate of redshirting increased after the change 
in cut date, let alone jump to the level of the late September/ early October births under the previous regime.

There is a chance that the lack of an adaptation by parents was because the new cut date was in some sense a surprise, in which case there might be greater effect in subsequent years. To test this possibility we checked against the redshirting patterns for another cohort, children born in the second year of the new regime, 2005. The pattern remained virtually unchanged. The results are depicted in Appendix Figure C1.

These findings suggest that children's absolute age, rather than age relative to classmates, plays the dominant role in the decision to redshirt. The policy-relevant implication is that the prevalence of redshirting is affected by the cut date, and in particular that a state that changes to an earlier cut date, as did North Carolina, should expect to experience a reduction in redshirting for better or worse. ${ }^{9}$

\section{Relevance to Policy on School Starting Age}

Students who attend public school in North Carolina are governed by the mandatory attendance laws, which specify the minimum age at which children may be enrolled in kindergarten, but allow parents to delay enrollment if they so choose. Delayed entry (redshirting) is quite common, especially for children who would be the youngest in their class if they started on time. But delayed entry was even more common before the state changed its cut day from October 17 to September 1. That result, demonstrated here by a simple comparison of redshirting patterns in the relevant years, was not obvious, since it is plausible a priori that redshirt decisions are primarily influenced by parents' concern about their child's age relative to classmates, rather than absolute age.

How should the reduction in redshirting be evaluated? The research literature has established that educational outcomes are affected by the child's age. In every measurable respect, older is

\footnotetext{
${ }^{9}$ It is possible that some parents were operating under a rule of thumb that children should not start kindergarten until they were 5 years old. Under the old regime, children with September and early October birthdates could start school at age 4, but that was no longer the case under the new regime. In that case, the calendar age would be serving as an absolute standard.
} 
better, at least in grade school. From the public perspective, "older is better" primarily pertains to relative standing, and is not of obvious concern to the public interest. But the literature also demonstrates certain patterns in redshirting; not only that children born just before the cut date are more likely to be held back, but also that white boys are more likely to be held back than other sex-race groups. Our findings reproduce and extend these findings. One implication is that for whites, the female-male gap in reading is reduced $11 \%$ by the net effect of parental decision making around school entry. Perhaps of greatest interest is a new discovery, that for each of the six groups defined by sex and race/ethnicity, the likelihood of redshirting is strongly inversely related to academic ability. The apparent effect is that redshirting patterns tend to benefit weaker students relative to stronger students. The social value of these effects can be disputed, but without a doubt the concern about boys lagging girls in school is frequently voiced (Orr 2011; Fortin, Oreopoulos and Phipps 2015), and an assist for weaker students seems desirable on the face of it. On the other hand, redshirting patterns tend to increase the blackwhite gap for males (though not much). And children who start school older are more likely to drop out before graduating, a clearly undesirable consequence of redshirting (Cook and Kang 2016).

Thus, when it comes to the patterns in academic outcomes, the change in cut date in North Carolina would be predicted to have a variety of effects, both positive and negative, through the mechanism of changes in redshirting. These effects are worth considering in a comprehensive evaluation of reforms in school attendance laws. 


\section{References}

Angrist, Joshua D. and Alan B. Krueger (1991) “Does Compulsory School Attendance Affect Schooling and Earnings?” Quarterly Journal of Economics 106(4):979-1014

Autor, David, David Figlio, Krzysztof Karbownik, Jeffrey Roth, Melanie Wasserman. (2016)

“Family Disadvantage and the Gender Gap in Behavioral and Educational Outcomes.” NBER Working Paper w22267, May.

Bassok, Daphna, and Sean F. Reardon. (2013) “Academic Redshirting” in Kindergarten: Prevalence, Patterns, and Implications.” Educational Evaluation and Policy Analysis 35.3: 283297.

Bedard, Kelly, and Elizabeth Dhuey. (2006) “The Persistence of Early Childhood Maturity: International Evidence of Long-run Age Effects.” Quarterly Journal of Economics 121.4: 14371472.

Bound, John, David A. Jaeger, and Regina M. Baker. (1995) "Problems with Instrumental Variables Estimation when the Correlation between the Instruments and the Endogenous Explanatory Variable is Weak.” Journal of the American Statistical Association 90.430: 443-450.

Buckles, Kasey S., and Daniel M. Hungerman. (2013) “Season of Birth and Later Outcomes: Old Questions, New Answers.” Review of Economics and Statistics 95.3: 711-724.

Carlsson, Magnus, Gordon B. Dahl, Björn Öckert, and Dan-Olof Rooth. (2015) “The Effect of Schooling on Cognitive Skills.” Review of Economics and Statistics 97.3: 533-547.

Cascio, Elizabeth U., and Diane Whitmore Schanzenbach. (2016) "First in the Class? Age and the Education Production Function.” Education Finance and Policy 11.3: 225-250.

Chetty, Raj, John N. Friedman, and Jonah E. Rockoff. (2014) “Measuring the Impacts of Teachers I: Evaluating Bias in Teacher Value-added Estimates.” American Economic Review 104.9: 2593-2632.

Clotfelter, Charles T., Helen F. Ladd, and Jacob L. Vigdor. (2009) “The Academic Achievement Gap in Grades 3 to 8.” Review of Economics and Statistics 91.2: 398-419. 
Cook, Philip J., and Songman Kang. (2016) "Birthdays, Schooling, and Crime: Regressiondiscontinuity Analysis of School Performance, Delinquency, Dropout, and Crime Initiation." American Economic Journal: Applied Economics 8.1: 33-57.

Deming, David, and Susan Dynarski. (2008) “The Lengthening of Childhood.” Journal of Economic Perspectives 22.3: 71-92.

Dhuey, Elizabeth, David Figlio, Krzysztof Karbownik, and Jeffrey Roth. (2017) "School Starting Age and Cognitive Development.” NBER Working Paper No. w23660.

Dhuey, Elizabeth, and Stephen Lipscomb. (2010) "Disabled or Young? Relative Age and Special Education Diagnoses in Schools." Economics of Education Review 29.5: 857-872.

DiPrete, Thomas A., and Jennifer L. Jennings. (2012) "Social and Behavioral Skills and the Gender Gap in Early Educational Achievement.” Social Science Research 41.1: 1-15.

Dobbie, Will, and Roland G. Fryer. (2011) “Are High-quality Schools Enough to Increase Achievement among the Poor? Evidence from the Harlem Children's Zone.” American Economic Journal: Applied Economics 3.3: 158-187.

Dobkin, Carlos, and Fernando Ferreira. (2010) "Do School Entry Laws Affect Educational Attainment and Labor Market Outcomes?” Economics of Education Review 29.1: 40-54.

Dodge, Kenneth A., Yu Bai, Helen F. Ladd, Clara G. Muschkin. (2016) "Impact of North Carolina's Early Childhood Programs and Policies on Educational Outcomes in Elementary School,” Child Development, Nov 2016.

Elder, Todd E. (2010) "The Importance of Relative Standards in ADHD Diagnoses: Evidence based on Exact Birth dates." Journal of Health Economics 29.5: 641-656.

Elder, Todd E., and Darren H. Lubotsky. (2009) “Kindergarten Entrance Age and Children’s Achievement Impacts of State Policies, Family Background, and Peers.” Journal of Human Resources 44.3: 641-683.

Fortin, Nicole M., Philip Oreopoulos, and Shelley Phipps. (2015) "Leaving Boys Behind: Gender Disparities in High Academic Achievement.” Journal of Human Resources, 50(3): 549579 
Redshirting Matters

Imbens, Guido W., and Joshua D. Angrist. (1994) "Identification and Estimation of Local Average Treatment Effects.” Econometrica 62.2: 467-475.

Orr, Amy J. (2011) "Gendered Capital: Childhood Socialization and the "Boy Crisis" in Education.” Sex Roles, 65: 271-284. 
Figure 1. Age of Grade 1 Entry

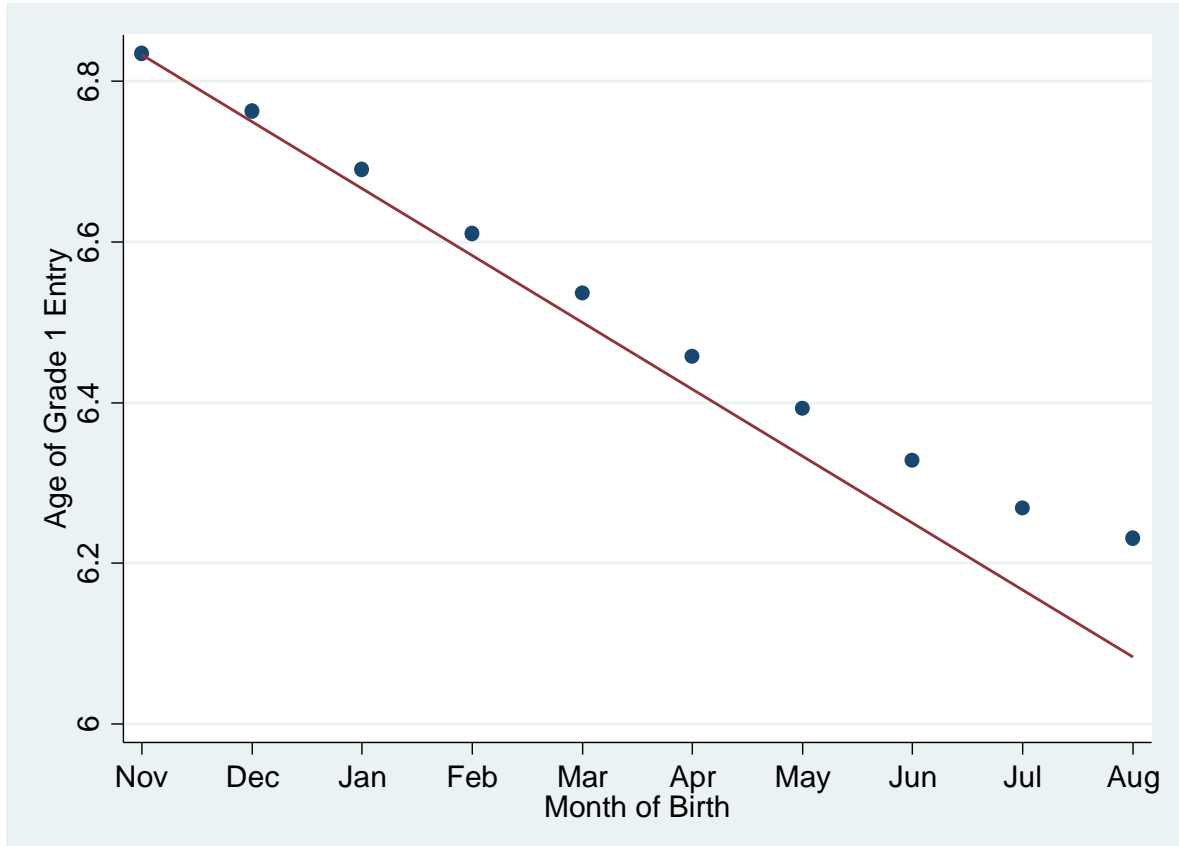

Note: Circles represent monthly averages of the grade 1 entry age for North Carolina public school students born between November 2003 and August 2004. The line represents the grade 1 entry age predicted by the month of birth. 
Figure 2. Pattern of Delayed School Entry

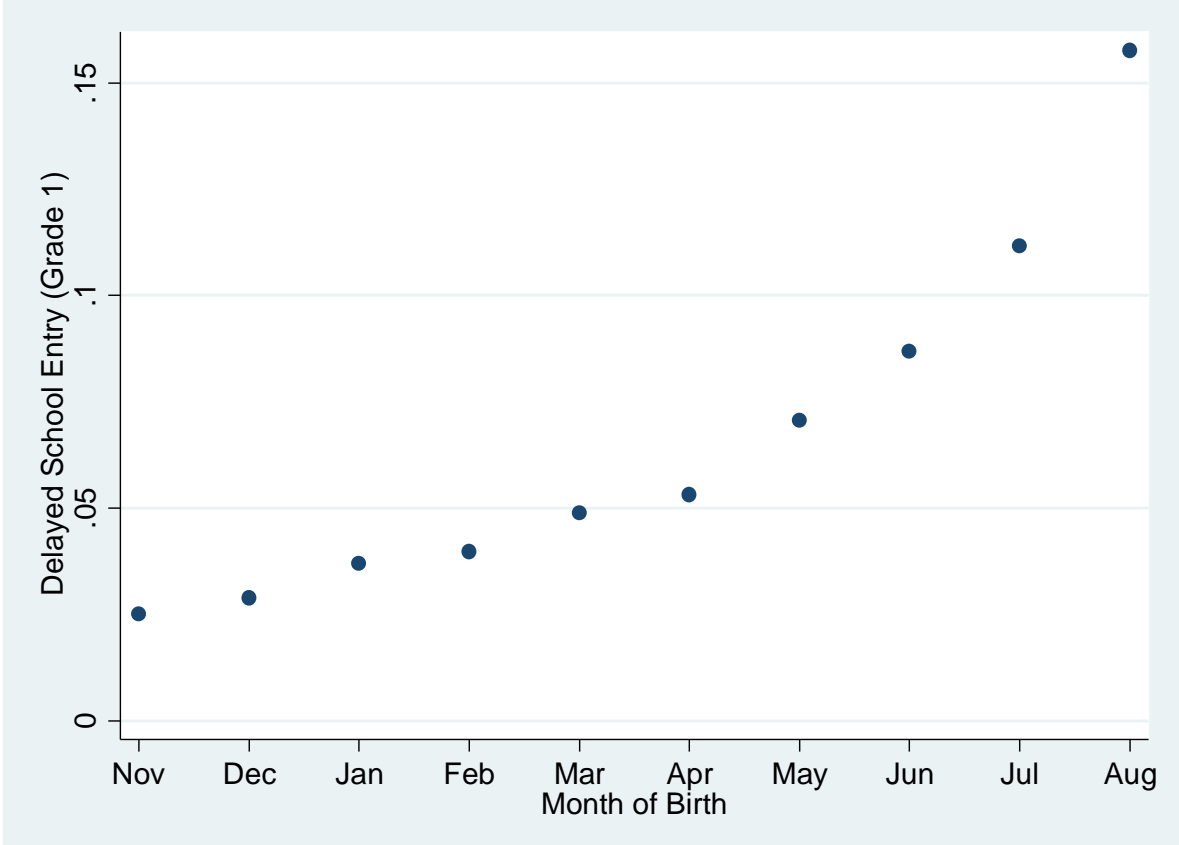

Note: Circles represent the rate of delayed grade 1 entry by the month of birth for North Carolina public school students born between November 2003 and August 2004. 
Figure 3. Average EOG 3 Reading and Math Scores by Month of Birth
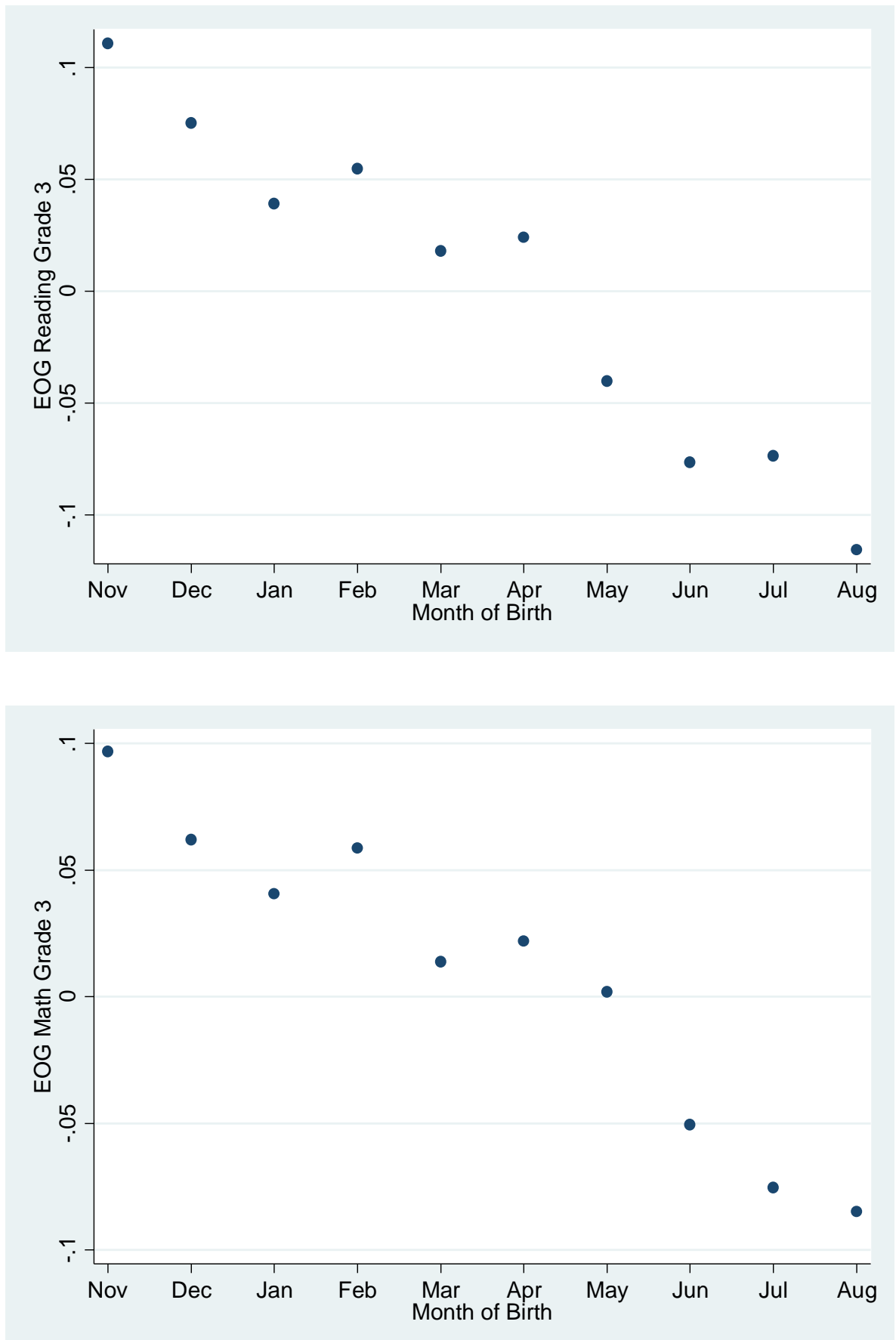

Note: Circles represent average EOG3 reading and math scores (standard normalized at the subject-year level) by the month of birth for North Carolina public school students born between November 2003 and August 2004. 
Figure 4. Share of Third Graders with Learning Disability

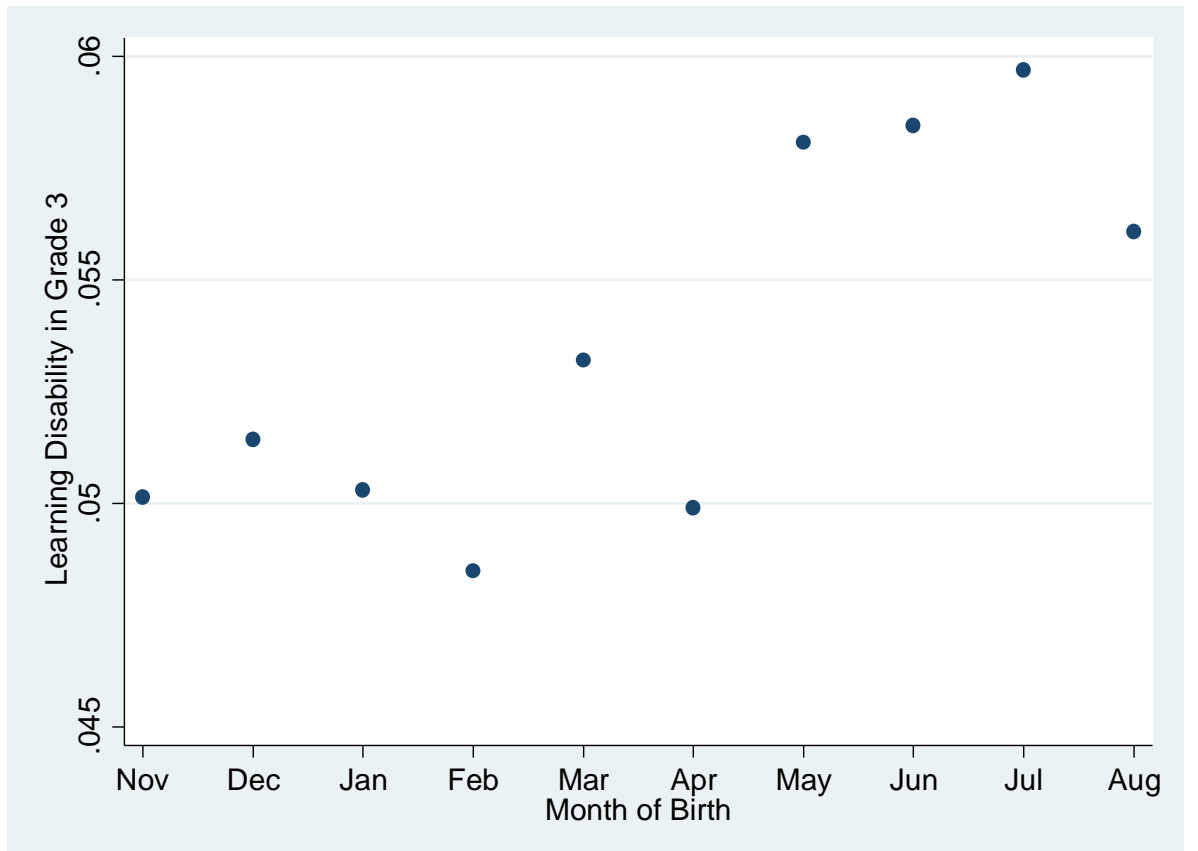

Note: Circles represent the share of third graders diagnosed as learning disabled by the month of birth for North Carolina public school students born between November 2003 and August 2004. 
Figure 5. Share of Third Graders with Speech Impairment

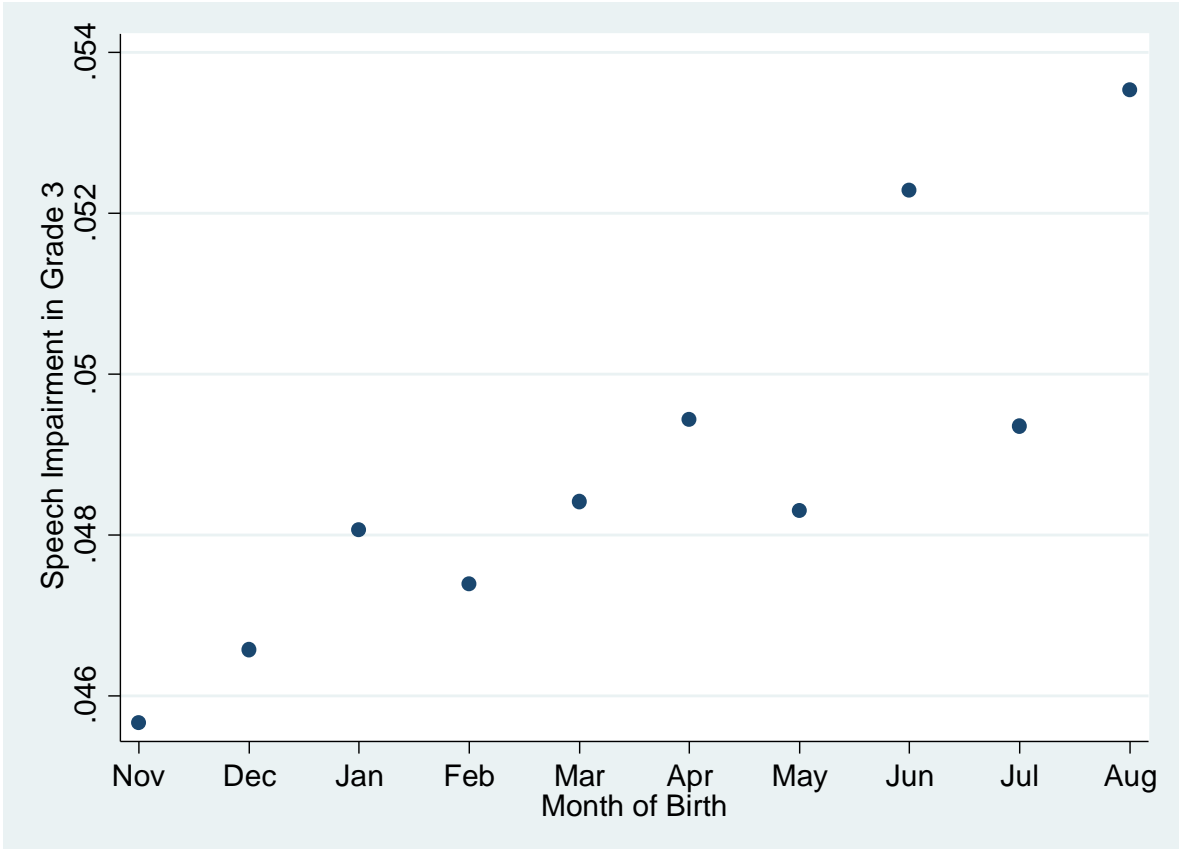

Note: Circles represent the share of third graders diagnosed as speech impaired by the month of birth for North Carolina public school students born between November 2003 and August 2004. 
Figure 6. Share of Third Graders Considered Academically and Intellectually Gifted (AIG)

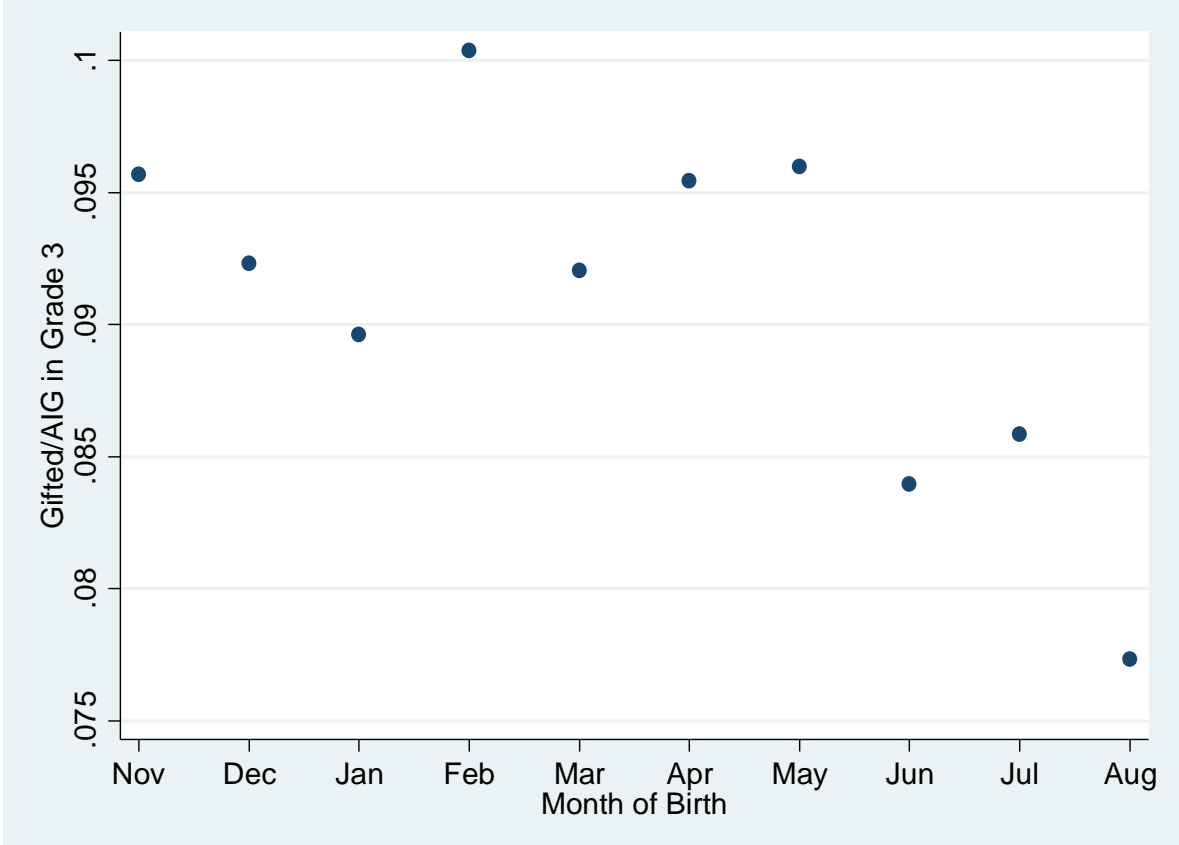

Note: Circles represent the share of third graders considered as academically and intellectually gifted (AIG) by the month of birth for North Carolina public school students born between November 2003 and August 2004. 
Figure 7. IV Estimates of School Starting Age Effect on EOG 3 Scores, by Race and Gender
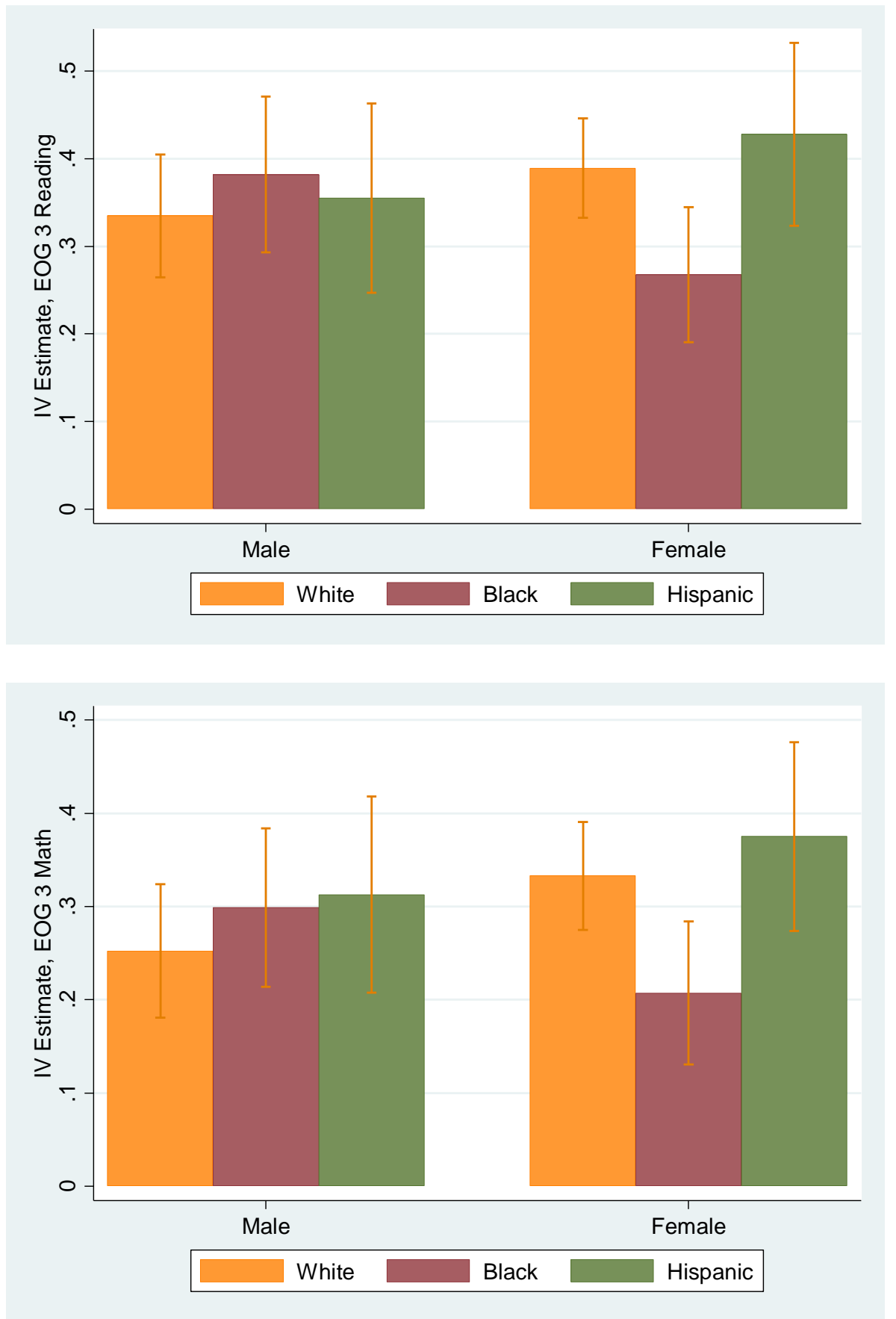

Note: Bars represent the IV estimate of school starting age effect, separately estimated from each race and gender group. Vertical bands show 95 percent confidence intervals. 
Figure 8. The Patterns of Delayed School Entry before and after the Cut Date Change

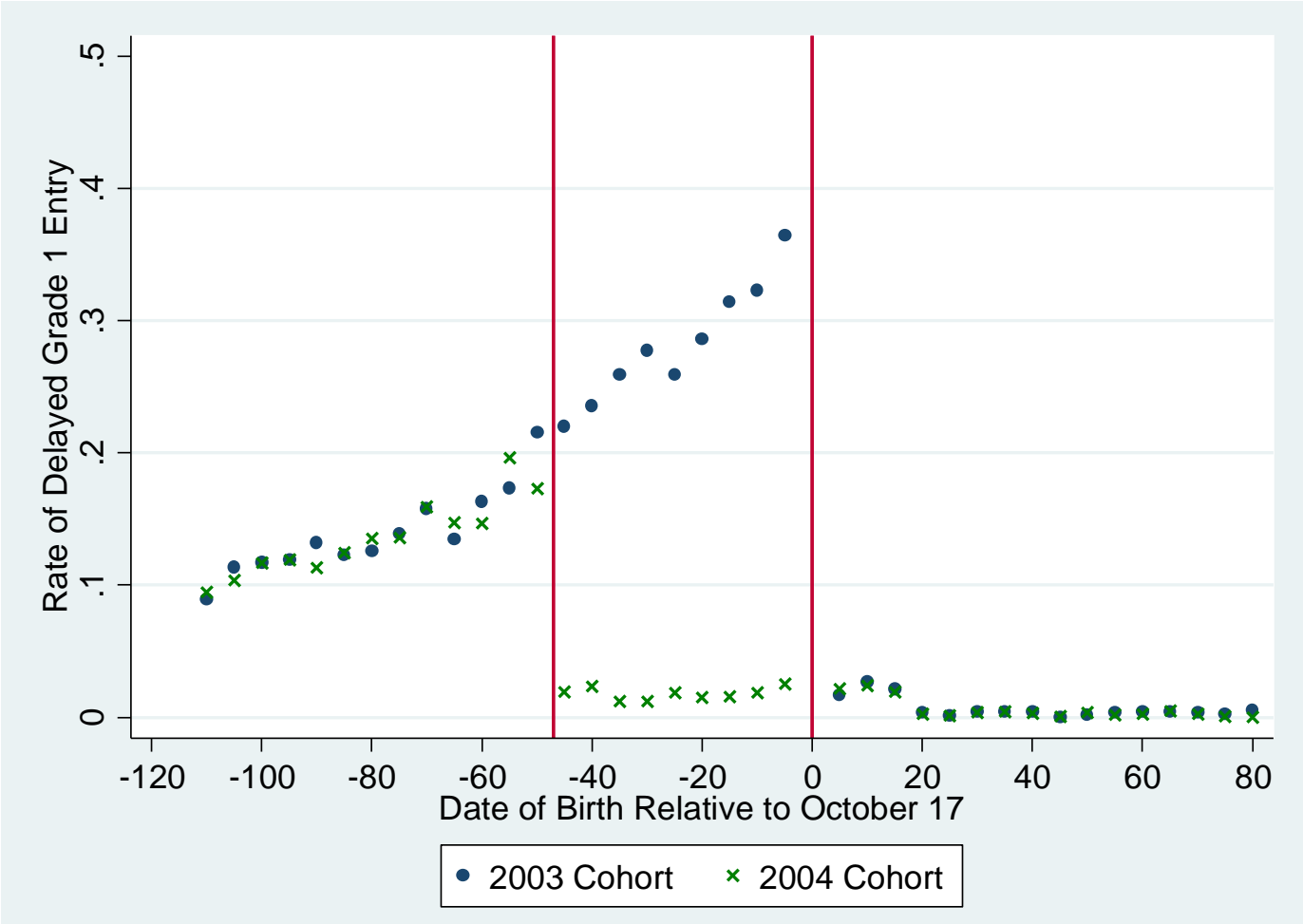

Note: Circles and crosses represent 5-day average rates of delayed grade 1 entry for the 2003 and 2004 cohorts, respectively. The two vertical lines correspond to the old cutoff date (October 17, day 0 ) and new cutoff date (September 1, day -47) for public school entry in North Carolina. 
Redshirting Matters

Table 1. Summary Statistics

\begin{tabular}{lcc}
\hline \hline & Mean & Std. Dev. \\
\hline Male & 0.507 & \\
White & 0.519 & \\
Black & 0.245 & \\
Hispanic & 0.155 & \\
Economic Disadvantage & 0.562 & \\
School Starting Age (Grade 1) & 6.507 & \multirow{2}{*}{0.359} \\
Grade 1 Entry & & \\
Early & 0.008 & \\
On-time & 0.925 & \\
Late & 0.067 & \\
EOG Reading z-Score, Grade 3 & 0.000 & 0.995 \\
EOG Math z-Score, Grade 3 & 0.007 & 0.994 \\
Learning Disability, Grade 3 & 0.054 & \\
Speech Impairment, Grade 3 & 0.049 & \\
Academically and Intellectually Gifted, Grade 3 & 0.091 & \\
Obs. & 85953 & \\
\hline
\end{tabular}

Note: Based on students born between November 2003 and August 2004, who were later enrolled in North Carolina public schools as first-graders. 
Table 2. Effects of School Starting Age on EOG3 scores and Exceptionality Status

\begin{tabular}{|c|c|c|c|c|c|}
\hline & \multicolumn{2}{|c|}{ EOG 3} & \multicolumn{3}{|c|}{ Exceptionality } \\
\hline & Reading & Math & LD & SI & Gifted \\
\hline \multicolumn{6}{|l|}{ (A) OLS } \\
\hline SSA & $\begin{array}{c}-0.035^{* * *} \\
(0.010)\end{array}$ & $\begin{array}{c}-0.051^{* * *} \\
(0.009)\end{array}$ & $\begin{array}{c}0.058 * * * \\
(0.003)\end{array}$ & $\begin{array}{c}-0.000 \\
(0.002)\end{array}$ & $\begin{array}{c}-0.012 * * * \\
(0.002)\end{array}$ \\
\hline Male & $\begin{array}{c}-0.160^{* * *} \\
(0.006)\end{array}$ & $\begin{array}{c}-0.021^{* * *} \\
(0.006)\end{array}$ & $\begin{array}{c}0.026 * * * \\
(0.002)\end{array}$ & $\begin{array}{c}0.029 * * * \\
(0.001)\end{array}$ & $\begin{array}{c}-0.004^{* *} \\
(0.002)\end{array}$ \\
\hline Black & $\begin{array}{c}-0.436 * * * \\
(0.009)\end{array}$ & $\begin{array}{c}-0.458 * * * \\
(0.008)\end{array}$ & $\begin{array}{c}-0.007^{* * *} \\
(0.002)\end{array}$ & $\begin{array}{c}-0.024^{* * *} \\
(0.002)\end{array}$ & $\begin{array}{c}-0.035 * * * \\
(0.002)\end{array}$ \\
\hline Hispanic & $\begin{array}{c}-0.391^{* * *} \\
(0.010)\end{array}$ & $\begin{array}{c}-0.192 * * * \\
(0.010)\end{array}$ & $\begin{array}{c}-0.013^{* * *} \\
(0.003)\end{array}$ & $\begin{array}{c}-0.031^{* * *} \\
(0.002)\end{array}$ & $\begin{array}{c}-0.027 * * * \\
(0.002)\end{array}$ \\
\hline Disadvantage & $\begin{array}{c}-0.599 * * * \\
(0.007)\end{array}$ & $\begin{array}{c}-0.610 * * * \\
(0.007)\end{array}$ & $\begin{array}{c}0.043^{* * *} \\
(0.002)\end{array}$ & $\begin{array}{c}0.013^{* * *} \\
(0.002)\end{array}$ & $\begin{array}{c}-0.121 * * * \\
(0.002)\end{array}$ \\
\hline Constant & $\begin{array}{c}0.815^{* * *} \\
(0.063)\end{array}$ & $\begin{array}{c}0.828 * * * \\
(0.061)\end{array}$ & $\begin{array}{c}-0.353^{* * *} \\
(0.019)\end{array}$ & $\begin{array}{c}0.040 * * * \\
(0.015)\end{array}$ & $\begin{array}{c}0.248 * * * \\
(0.014)\end{array}$ \\
\hline Obs. & 81,956 & 82,466 & 85,953 & 85,953 & 85,953 \\
\hline \multicolumn{6}{|l|}{ (B) IV (Second Stage) } \\
\hline SSA & $\begin{array}{c}0.359 * * * \\
(0.016)\end{array}$ & $\begin{array}{c}0.298 * * * \\
(0.016)\end{array}$ & $\begin{array}{c}-0.016^{* * *} \\
(0.004)\end{array}$ & $\begin{array}{c}-0.010 * * * \\
(0.004)\end{array}$ & $\begin{array}{c}0.023 * * * \\
(0.005)\end{array}$ \\
\hline Male & $\begin{array}{c}-0.175^{* * *} \\
(0.006)\end{array}$ & $\begin{array}{c}-0.035^{* * *} \\
(0.006)\end{array}$ & $\begin{array}{c}0.029 * * * \\
(0.002)\end{array}$ & $\begin{array}{c}0.029 * * * \\
(0.001)\end{array}$ & $\begin{array}{c}-0.006 * * * \\
(0.002)\end{array}$ \\
\hline Black & $\begin{array}{c}-0.427^{* * *} \\
(0.009)\end{array}$ & $\begin{array}{c}-0.450 * * * \\
(0.009)\end{array}$ & $\begin{array}{c}-0.009 * * * \\
(0.002)\end{array}$ & $\begin{array}{c}-0.024^{* * *} \\
(0.002)\end{array}$ & $\begin{array}{c}-0.034^{* * *} \\
(0.002)\end{array}$ \\
\hline Hispanic & $\begin{array}{c}-0.382^{* * *} \\
(0.010)\end{array}$ & $\begin{array}{c}-0.183^{* * *} \\
(0.010)\end{array}$ & $\begin{array}{c}-0.015^{* * *} \\
(0.003)\end{array}$ & $\begin{array}{c}-0.032 * * * \\
(0.002)\end{array}$ & $\begin{array}{c}-0.026 * * * \\
(0.002)\end{array}$ \\
\hline Disadvantage & $\begin{array}{c}-0.608 * * * \\
(0.007)\end{array}$ & $\begin{array}{c}-0.617^{* * *} \\
(0.007)\end{array}$ & $\begin{array}{c}0.045^{* * *} \\
(0.002)\end{array}$ & $\begin{array}{c}0.013^{* * *} \\
(0.002)\end{array}$ & $\begin{array}{c}-0.122 * * * \\
(0.002)\end{array}$ \\
\hline Constant & $\begin{array}{c}-1.738^{* * *} \\
(0.102)\end{array}$ & $\begin{array}{c}-1.434^{* * *} \\
(0.102)\end{array}$ & $\begin{array}{c}0.124^{* * *} \\
(0.025)\end{array}$ & $\begin{array}{c}0.101^{* * *} \\
(0.024)\end{array}$ & $\begin{array}{c}0.022 \\
(0.030)\end{array}$ \\
\hline Obs. & 81,956 & 82,466 & 85,953 & 85,953 & 85,953 \\
\hline First-stage Partial $\mathrm{R}^{2}$ & 0.3340 & 0.3296 & 0.3128 & 0.3128 & 0.3128 \\
\hline F-stat. for IV joint significance & 4746.1 & 4672.4 & 4508.2 & 4508.2 & 4508.2 \\
\hline
\end{tabular}

Note: Robust standard errors in parentheses. ${ }^{* * *} \mathrm{p}<0.01,{ }^{* *} \mathrm{p}<0.05,{ }^{*} \mathrm{p}<0.1$

An indicator for "other race” (Asian and American Indian) was included in all specifications. 
Table 3. IV Estimates for subsamples defined by Race and Gender

\begin{tabular}{lcc}
\hline \hline & \multicolumn{2}{c}{ EOG 3 } \\
& Reading & Math \\
\hline (A) Full Sample & $0.359 * * *$ & $0.298^{* * *}$ \\
& $(0.016)$ & $(0.016)$ \\
Obs. & 81,956 & 82,466 \\
\hline (B) White Male & $0.335^{* * *}$ & $0.252^{* * *}$ \\
& $(0.036)$ & $(0.036)$ \\
Obs. & 21,683 & 21,878 \\
\hline (C) Black Male & $0.382 * * *$ & $0.299 * * *$ \\
& $(0.045)$ & $(0.043)$ \\
Obs. & 9,670 & 9,769 \\
\hline (D) Hispanic Male & $0.355 * * *$ & $0.313^{* * *}$ \\
& $(0.055)$ & $(0.054)$ \\
Obs. & 6,338 & 6,420 \\
\hline (E) White Female & $0.389 * * *$ & $0.333^{* * *}$ \\
& $(0.029)$ & $(0.029)$ \\
Obs. & 21,195 & 21,252 \\
\hline (F) Black Female & $0.267 * * *$ & $0.207 * * *$ \\
& $(0.039)$ & $(0.039)$ \\
Obs. & 10,081 & 10,094 \\
\hline (G) Hispanic Female & $0.428 * * *$ & $0.375^{* * *}$ \\
& $(0.053)$ & $(0.052)$ \\
Obs. & 6,328 & 6,364 \\
\hline Note: Each pang
\end{tabular}

Note: Each panel presents estimation results from each race-by-gender group. Robust standard errors in parentheses. ${ }^{* * *} \mathrm{p}<0.01,{ }^{* *} \mathrm{p}<0.05,{ }^{*} \mathrm{p}<0.1$ 
Table 4. Effect of Redshirting and Greenshirting on EOG 3 Reading and Math Scores

\begin{tabular}{lccccccc}
\hline \hline & & White & $\begin{array}{c}\text { Black } \\
\text { Male }\end{array}$ & $\begin{array}{c}\text { Hisp. } \\
\text { Male }\end{array}$ & $\begin{array}{c}\text { White } \\
\text { Female }\end{array}$ & $\begin{array}{c}\text { Black } \\
\text { Female }\end{array}$ & $\begin{array}{c}\text { Hisp. } \\
\text { Female }\end{array}$ \\
\hline (A) Grade 1 Entry & & & & & & & \\
\% Early & $0.8 \%$ & $0.7 \%$ & $0.8 \%$ & $0.9 \%$ & $0.7 \%$ & $1.0 \%$ & $0.9 \%$ \\
\% on time & $92.5 \%$ & $89.5 \%$ & $91.5 \%$ & $91.3 \%$ & $94.5 \%$ & $95.0 \%$ & $94.0 \%$ \\
\% Late & $6.7 \%$ & $9.9 \%$ & $7.7 \%$ & $7.8 \%$ & $4.8 \%$ & $4.0 \%$ & $5.0 \%$ \\
\hline (B) EOG 3 Reading & & & & & & & \\
Actual Mean & 0.000 & 0.219 & -0.517 & -0.469 & 0.371 & -0.318 & -0.351 \\
Hypothetical Mean & -0.016 & 0.192 & -0.536 & -0.489 & 0.360 & -0.325 & -0.361 \\
Diff. & -0.016 & -0.027 & -0.019 & -0.019 & -0.011 & -0.007 & -0.010 \\
\hline (C) EOG 3 Math & & & & & & & \\
Actual Mean & 0.007 & 0.265 & -0.501 & -0.229 & 0.278 & -0.434 & -0.249 \\
Hypothetical Mean & -0.007 & 0.241 & -0.517 & -0.246 & 0.269 & -0.439 & -0.258 \\
Diff. & -0.014 & -0.023 & -0.016 & -0.016 & -0.009 & -0.006 & -0.009 \\
\hline
\end{tabular}

Note: “Actual Mean" corresponds to the observed mean EOG 3 reading and math scores and "Hypothetical Mean" the mean of age-corrected EOG 3 reading and math scores. See text for details. 
Table 5. Actual and Age-corrected Achievement Gap by Gender and Race, Mean Difference

\begin{tabular}{llcccc}
\hline \hline & & \multicolumn{2}{c}{ EOG 3 Reading } & \multicolumn{2}{c}{ EOG 3 Math } \\
& & Actual & Corrected & Actual & Corrected \\
\hline Male-Female Gap & (White Female -White Male) & 0.151 & 0.168 & 0.013 & 0.028 \\
& (Black Female - Black Male) & 0.199 & 0.211 & 0.068 & 0.078 \\
\multirow{2}{*}{ White-Black Gap } & (Hispanic Female - Hispanic Male) & 0.119 & 0.128 & -0.020 & -0.012 \\
\multirow{2}{*}{ White-Hispanic Gap } & (White Male - Black Male) & 0.737 & 0.728 & 0.766 & 0.759 \\
& (White Female -Black Female) & 0.689 & 0.685 & 0.712 & 0.708 \\
& (White Male - Hispanic Male) & 0.689 & 0.681 & 0.494 & 0.487 \\
\hline
\end{tabular}

Note: "Actual” corresponds to the observed gap in EOG 3 reading and math achievement, and "Corrected" the achievement gap that remain after the effects of redshirting and greenshirting are accounted for. See text for details. 
Table 6: Determinants of Academic Redshirting, Logit Estimation

\begin{tabular}{|c|c|c|c|c|}
\hline Outcome: & \multicolumn{4}{|c|}{ Entering First Grade Older than Expected } \\
\hline \multicolumn{5}{|c|}{ Month of Birth (Baseline: November) } \\
\hline December & $\begin{array}{c}0.069 \\
(0.111)\end{array}$ & $\begin{array}{c}0.071 \\
(0.111)\end{array}$ & $\begin{array}{c}0.064 \\
(0.111)\end{array}$ & $\begin{array}{c}0.029 \\
(0.113)\end{array}$ \\
\hline January & $\begin{array}{c}0.422 * * * \\
(0.104)\end{array}$ & $\begin{array}{c}0.427 * * * \\
(0.104)\end{array}$ & $\begin{array}{c}0.423 * * * \\
(0.104)\end{array}$ & $\begin{array}{c}0.375 * * * \\
(0.105)\end{array}$ \\
\hline February & $\begin{array}{c}0.555 * * * \\
(0.102)\end{array}$ & $\begin{array}{c}0.555^{* * *} \\
(0.102)\end{array}$ & $\begin{array}{c}0.554 * * * \\
(0.102)\end{array}$ & $\begin{array}{c}0.508 * * * \\
(0.103)\end{array}$ \\
\hline March & $\begin{array}{c}0.708^{* * * *} \\
(0.099)\end{array}$ & $\begin{array}{c}0.699 * * * \\
(0.099)\end{array}$ & $\begin{array}{c}0.700^{* * * *} \\
(0.099)\end{array}$ & $\begin{array}{c}0.622 * * * \\
(0.100)\end{array}$ \\
\hline April & $\begin{array}{c}0.828 * * * \\
(0.097)\end{array}$ & $\begin{array}{c}0.825 * * * \\
(0.097)\end{array}$ & $\begin{array}{c}0.831 * * * \\
(0.097)\end{array}$ & $\begin{array}{c}0.755^{* * *} \\
(0.099)\end{array}$ \\
\hline May & $\begin{array}{c}1.168^{* * *} \\
(0.093)\end{array}$ & $\begin{array}{c}1.167 * * * \\
(0.093)\end{array}$ & $\begin{array}{c}1.170^{* * * *} \\
(0.093)\end{array}$ & $\begin{array}{c}1.060 * * * \\
(0.095)\end{array}$ \\
\hline June & $\begin{array}{c}1.420 * * * \\
(0.091)\end{array}$ & $\begin{array}{c}1.433 * * * \\
(0.091)\end{array}$ & $\begin{array}{c}1.432 * * * \\
(0.091)\end{array}$ & $\begin{array}{c}1.302 * * * \\
(0.092)\end{array}$ \\
\hline July & $\begin{array}{c}1.742 * * * \\
(0.088)\end{array}$ & $\begin{array}{c}1.747 * * * \\
(0.088)\end{array}$ & $\begin{array}{c}1.748 * * * \\
(0.088)\end{array}$ & $\begin{array}{c}1.635 * * * \\
(0.090)\end{array}$ \\
\hline August & $\begin{array}{c}2.128 * * * \\
(0.086)\end{array}$ & $\begin{array}{c}2.150 * * * \\
(0.086)\end{array}$ & $\begin{array}{c}2.154 * * * \\
(0.087)\end{array}$ & $\begin{array}{c}2.041 * * * \\
(0.088)\end{array}$ \\
\hline \multicolumn{5}{|c|}{ Race x Gender (Baseline: White Female) } \\
\hline White Male & & $\begin{array}{c}0.819 * * * \\
(0.042)\end{array}$ & $\begin{array}{c}0.821^{* * *} \\
(0.042)\end{array}$ & $\begin{array}{c}0.752 * * * \\
(0.044)\end{array}$ \\
\hline Black Male & & $\begin{array}{c}0.487 * * * \\
(0.054)\end{array}$ & $\begin{array}{c}0.303^{* * *} \\
(0.056)\end{array}$ & $\begin{array}{c}-0.237 * * * \\
(0.059)\end{array}$ \\
\hline Hispanic Male & & $\begin{array}{c}0.513 * * * \\
(0.061)\end{array}$ & $\begin{array}{c}0.302 * * * \\
(0.064)\end{array}$ & $\begin{array}{l}-0.057 \\
(0.066)\end{array}$ \\
\hline Black Female & & $\begin{array}{c}-0.220^{* * * *} \\
(0.065)\end{array}$ & $\begin{array}{c}-0.408 * * * \\
(0.067)\end{array}$ & $\begin{array}{c}-0.779 * * * \\
(0.069)\end{array}$ \\
\hline Hispanic Female & & $\begin{array}{c}0.071 \\
(0.070)\end{array}$ & $\begin{array}{c}-0.139 * \\
(0.072)\end{array}$ & $\begin{array}{c}-0.454 * * * \\
(0.074)\end{array}$ \\
\hline Economic Disadvantage & & & $\begin{array}{c}0.418^{* * * *} \\
(0.034)\end{array}$ & $\begin{array}{c}-0.162 * * * \\
(0.037)\end{array}$ \\
\hline EOG 3 Reading (Hypothetical) & & & & $\begin{array}{c}-0.583 * * * \\
(0.023)\end{array}$ \\
\hline EOG 3 Math (Hypothetical) & & & & $\begin{array}{c}-0.374 * * * \\
(0.024)\end{array}$ \\
\hline Constant & $\begin{array}{c}-3.894 * * * \\
(0.081)\end{array}$ & $\begin{array}{c}-4.268^{* * * *} \\
(0.087)\end{array}$ & $\begin{array}{c}-4.432 * * * \\
(0.088)\end{array}$ & $\begin{array}{c}-4.139 * * * \\
(0.090)\end{array}$ \\
\hline Obs. & 81,867 & 81,867 & 81,867 & 81,867 \\
\hline
\end{tabular}


Redshirting Matters

Note: Standard errors in parentheses. ${ }^{* * *} \mathrm{p}<0.01,{ }^{* *} \mathrm{p}<0.05,{ }^{*} \mathrm{p}<0.1$

Indicators for "Other race X male” and "Other race X female” were included in all specifications. 
Table 7: Determinants of Redshirting, by Race-Sex Group

\begin{tabular}{|c|c|c|c|c|c|c|}
\hline \multirow{2}{*}{$\begin{array}{l}\text { Outcome: } \\
\text { Sample: }\end{array}$} & \multicolumn{6}{|c|}{ Entering First Grade Older than Expected } \\
\hline & $\begin{array}{c}\text { White } \\
\text { Male }\end{array}$ & $\begin{array}{l}\text { Black } \\
\text { Male }\end{array}$ & $\begin{array}{l}\text { Hisp. } \\
\text { Male }\end{array}$ & $\begin{array}{l}\text { White } \\
\text { Female }\end{array}$ & $\begin{array}{c}\text { Black } \\
\text { Female }\end{array}$ & $\begin{array}{l}\text { Hisp. } \\
\text { Female }\end{array}$ \\
\hline \multicolumn{7}{|c|}{ Month of Birth (Baseline: November) } \\
\hline December & $\begin{array}{c}0.272 \\
(0.220)\end{array}$ & $\begin{array}{l}-0.236 \\
(0.270)\end{array}$ & $\begin{array}{l}-0.164 \\
(0.311)\end{array}$ & $\begin{array}{c}0.466 \\
(0.337)\end{array}$ & $\begin{array}{c}0.281 \\
(0.332)\end{array}$ & $\begin{array}{l}-0.359 \\
(0.366)\end{array}$ \\
\hline January & $\begin{array}{c}0.711 * * * \\
(0.206)\end{array}$ & $\begin{array}{c}0.250 \\
(0.243)\end{array}$ & $\begin{array}{l}-0.210 \\
(0.306)\end{array}$ & $\begin{array}{c}0.880 * * * \\
(0.317)\end{array}$ & $\begin{array}{c}0.480 \\
(0.326)\end{array}$ & $\begin{array}{l}-0.426 \\
(0.371)\end{array}$ \\
\hline February & $\begin{array}{c}0.756^{* * *} \\
(0.204)\end{array}$ & $\begin{array}{c}0.306 \\
(0.244)\end{array}$ & $\begin{array}{c}0.080 \\
(0.292)\end{array}$ & $\begin{array}{c}1.131^{* * *} \\
(0.308)\end{array}$ & $\begin{array}{c}0.346 \\
(0.338)\end{array}$ & $\begin{array}{c}0.294 \\
(0.333)\end{array}$ \\
\hline March & $\begin{array}{c}0.885 * * * \\
(0.198)\end{array}$ & $\begin{array}{c}0.568 * * \\
(0.232)\end{array}$ & $\begin{array}{c}0.143 \\
(0.284)\end{array}$ & $\begin{array}{c}1.054 * * * \\
(0.307)\end{array}$ & $\begin{array}{c}0.659 * * \\
(0.321)\end{array}$ & $\begin{array}{c}0.279 \\
(0.322)\end{array}$ \\
\hline April & $\begin{array}{c}1.060^{* * * *} \\
(0.194)\end{array}$ & $\begin{array}{c}0.627^{* * *} \\
(0.233)\end{array}$ & $\begin{array}{c}0.559 * * \\
(0.261)\end{array}$ & $\begin{array}{c}1.068^{* * * *} \\
(0.306)\end{array}$ & $\begin{array}{c}0.459 \\
(0.328)\end{array}$ & $\begin{array}{c}0.441 \\
(0.317)\end{array}$ \\
\hline May & $\begin{array}{c}1.621^{* * *} \\
(0.185)\end{array}$ & $\begin{array}{c}0.607^{* * *} \\
(0.231)\end{array}$ & $\begin{array}{c}0.643 * * \\
(0.253)\end{array}$ & $\begin{array}{c}1.562 * * * \\
(0.293)\end{array}$ & $\begin{array}{c}0.787 * * \\
(0.310)\end{array}$ & $\begin{array}{c}0.480 \\
(0.313)\end{array}$ \\
\hline June & $\begin{array}{c}1.969 * * * \\
(0.182)\end{array}$ & $\begin{array}{c}0.677 * * * \\
(0.226)\end{array}$ & $\begin{array}{c}0.769 * * * \\
(0.255)\end{array}$ & $\begin{array}{c}2.025 * * * \\
(0.285)\end{array}$ & $\begin{array}{c}0.979 * * * \\
(0.300)\end{array}$ & $\begin{array}{c}0.013 \\
(0.331)\end{array}$ \\
\hline July & $\begin{array}{c}2.407^{* * *} \\
(0.178)\end{array}$ & $\begin{array}{c}1.002 * * * \\
(0.215)\end{array}$ & $\begin{array}{c}0.854^{* * *} \\
(0.246)\end{array}$ & $\begin{array}{c}2.381^{* * *} \\
(0.281)\end{array}$ & $\begin{array}{c}0.698^{* *} \\
(0.306)\end{array}$ & $\begin{array}{c}0.437 \\
(0.303)\end{array}$ \\
\hline August & $\begin{array}{c}2.876 * * * \\
(0.176)\end{array}$ & $\begin{array}{c}1.109 * * * \\
(0.214)\end{array}$ & $\begin{array}{c}1.109 * * * \\
(0.239)\end{array}$ & $\begin{array}{c}2.853 * * * \\
(0.278)\end{array}$ & $\begin{array}{c}1.229 * * * \\
(0.293)\end{array}$ & $\begin{array}{c}1.001^{* * *} \\
(0.284)\end{array}$ \\
\hline Economic Disadvantage & $\begin{array}{c}-0.260 * * * \\
(0.056)\end{array}$ & $\begin{array}{c}0.361^{* *} \\
(0.156)\end{array}$ & $\begin{array}{c}-0.377^{* *} \\
(0.171)\end{array}$ & $\begin{array}{l}-0.049 \\
(0.077)\end{array}$ & $\begin{array}{c}0.104 \\
(0.209)\end{array}$ & $\begin{array}{l}-0.186 \\
(0.223)\end{array}$ \\
\hline EOG 3 Reading (Predicted) & $\begin{array}{c}-0.384 * * * \\
(0.037)\end{array}$ & $\begin{array}{c}-0.785^{* * *} \\
(0.064)\end{array}$ & $\begin{array}{c}-0.608 * * * \\
(0.075)\end{array}$ & $\begin{array}{c}-0.642 * * * \\
(0.052)\end{array}$ & $\begin{array}{c}-0.889 * * * \\
(0.087)\end{array}$ & $\begin{array}{c}-0.745 * * * \\
(0.094)\end{array}$ \\
\hline EOG 3 Math (Predicted) & $\begin{array}{c}-0.295^{* * *} \\
(0.037)\end{array}$ & $\begin{array}{c}-0.776 * * * \\
(0.074)\end{array}$ & $\begin{array}{c}-0.433^{* * *} \\
(0.079)\end{array}$ & $\begin{array}{c}-0.305^{* * *} \\
(0.054)\end{array}$ & $\begin{array}{c}-0.875 * * * \\
(0.102)\end{array}$ & $\begin{array}{c}-0.454^{* * *} \\
(0.101)\end{array}$ \\
\hline Constant & $\begin{array}{c}-3.853^{* * *} \\
(0.170)\end{array}$ & $\begin{array}{c}-5.110 * * * \\
(0.243)\end{array}$ & $\begin{array}{c}-3.511^{* * *} \\
(0.257)\end{array}$ & $\begin{array}{c}-4.823^{* * * *} \\
(0.272)\end{array}$ & $\begin{array}{c}-5.692 * * * \\
(0.330)\end{array}$ & $\begin{array}{c}-4.037 * * * \\
(0.323)\end{array}$ \\
\hline Obs. & 21,662 & 9,650 & 6,333 & 21,179 & 10,062 & 6,326 \\
\hline
\end{tabular}

Note: Standard errors in parentheses. ${ }^{* * *} \mathrm{p}<0.01,{ }^{* *} \mathrm{p}<0.05,{ }^{*} \mathrm{p}<0.1$

Indicators for "Other race X male" and "Other race X female" were included in all specifications. 
Appendix Table A1. Effect of Redshirting on EOG 3 Scores using Group-specific IV Estimates of School Starting Age Effect

\begin{tabular}{lccccccc}
\hline \hline & & White & Black & Hisp. & White & Black & Hisp. \\
& & Male & Male & Male & Female & Female & Female \\
\hline (A) Grade 1 Entry & & & & & & & \\
\% Early & $0.8 \%$ & $0.7 \%$ & $0.8 \%$ & $0.9 \%$ & $0.7 \%$ & $1.0 \%$ & $0.9 \%$ \\
\% on time & $92.5 \%$ & $89.5 \%$ & $91.5 \%$ & $91.3 \%$ & $94.5 \%$ & $95.0 \%$ & $94.0 \%$ \\
\% Late & $6.7 \%$ & $9.9 \%$ & $7.7 \%$ & $7.8 \%$ & $4.8 \%$ & $4.0 \%$ & $5.0 \%$ \\
\hline (B) EOG 3 Reading & & & & & & & \\
Actual Mean & 0.000 & 0.219 & -0.517 & -0.469 & 0.371 & -0.318 & -0.351 \\
Hypothetical Mean & -0.016 & 0.194 & -0.538 & -0.488 & 0.359 & -0.323 & -0.363 \\
Diff. & -0.016 & -0.026 & -0.020 & -0.019 & -0.012 & -0.005 & -0.012 \\
\hline (C) EOG 3 Math & & & & & & & \\
Actual Mean & 0.007 & 0.265 & -0.501 & -0.229 & 0.278 & -0.434 & -0.249 \\
Hypothetical Mean & -0.007 & 0.245 & -0.517 & -0.247 & 0.268 & -0.438 & -0.260 \\
Diff. & -0.014 & -0.020 & -0.016 & -0.017 & -0.010 & -0.004 & -0.011 \\
\hline
\end{tabular}

Note: “Actual Mean" corresponds to the observed mean EOG 3 reading and math scores and "Hypothetical Mean" the mean of age-corrected EOG 3 reading and math scores. Group-specific IV estimates are used to correct the effect of redshirting and greenshirting on EOG 3 reading and math achievement levels. Robust standard errors in parentheses. ${ }^{* * *} \mathrm{p}<0.01,{ }^{* *} \mathrm{p}<0.05,{ }^{*} \mathrm{p}<0.1$ 


\section{Appendix B: Regression Discontinuity Analysis}

In addition to the IV analysis presented in the main text, we also ran a regression discontinuity analysis on North Carolina students born near the school entry cutoff date. Specifically, we compare the set of schooling outcomes between children who were born in August and September 2004 and later attended North Carolina public schools for grades 1-3 by estimating the equation below:

$$
y_{i}=\alpha_{0}+\alpha_{1} D_{i}+\beta X_{i}+\epsilon_{i}
$$

where $y_{i}$ represents the outcome of interest for student i (i.e., EOG3 reading and math achievement scores, learning disability and speech impairment, and AIG status in grade 3 ). $D_{i}$ is the binary indicator for September-births, and $X_{i}$ represents the set of individual covariates (raceby-gender and economic disadvantage indicators). Since the school entry cutoff date (September 1) creates a one-year difference in the timing of school entry eligibility among children of similar age, this comparison amounts to a regression discontinuity analysis with a rectangular kernel, where all students born in August and September are given equal weights. In particular, it represents the causal, intention-to-treat effect on educational outcomes of receiving school entry eligibility a year earlier than a comparable control group.

The IV analysis presented in the main text estimates the effect of school starting age on early educational outcomes by comparing children born between November 2003 and August 2004, most of whom are in the same academic cohort but differ in their school entry age because of their birth month. On the other hand, the RD analysis compares educational outcomes of Augustand September-borns, who should be very much similar in individual characteristics but are expected to be placed in different academic cohorts. Although the two study designs differ (intracohort vs. inter-cohort comparison), they both exploit the plausibly exogenous variation in students' timing of birth relative to the legal school entry cutoff date to estimate the causal effect of school entry timing on educational outcomes.

Estimation results are presented in Appendix Table B1. First row corresponds to estimates obtained from the full sample, and subsequent rows show estimation results obtained from each race-gender group separately. From the full sample, we observe a large discontinuity in school starting age ( 0.72 year) at the cutoff date, but this discontinuity is noticeably smaller than a full 
year difference, suggesting a non-negligible rate of non-compliance (mainly in the form of academic redshirting). The estimated discontinuities substantially vary across different racegender groups, ranging from 0.63 year for white males to 0.80 year for black females. The pattern of age discontinuity across different race-gender groups strongly suggest that academic redshirting is more common for males than females, and more common for whites than blacks and Hispanics. Turning to the discontinuities in academic achievement and exceptionality status at the cutoff date, we find that students born just after the cut date perform significantly better on the EOG 3 achievement tests, are less likely to be diagnosed as learning disabled or speech impaired, and more likely to be considered academically and intellectually gifted in grade 3 . These findings are consistent with the IV estimation results presented in the main text. 
Redshirting Matters

Appendix Table B1. Regression Discontinuity Estimates

\begin{tabular}{lccccccc}
\hline \hline & Starting Age & \multicolumn{2}{c}{ EOG 3 } & \multicolumn{5}{c}{ Exceptionality } \\
& Grade 1 & Reading & Math & LD & SI & Gifted & Obs. \\
\hline Full Sample & 0.723 & 0.246 & 0.219 & -0.011 & -0.013 & -0.010 & 17,995 \\
& $(0.005)$ & $(0.015)$ & $(0.015)$ & $(0.003)$ & $(0.003)$ & $(0.004)$ & \\
White Male & 0.630 & 0.234 & 0.190 & -0.011 & -0.018 & -0.010 & 4,694 \\
& $(0.011)$ & $(0.028)$ & $(0.028)$ & $(0.007)$ & $(0.007)$ & $(0.008)$ & \\
Black Male & 0.753 & 0.243 & 0.180 & -0.003 & -0.021 & 0.005 & 2,186 \\
& $(0.014)$ & $(0.042)$ & $(0.041)$ & $(0.011)$ & $(0.010)$ & $(0.008)$ & \\
Hispanic Male & 0.802 & 0.206 & 0.202 & -0.004 & -0.025 & 0.002 & 1,524 \\
& $(0.018)$ & $(0.051)$ & $(0.048)$ & $(0.014)$ & $(0.011)$ & $(0.009)$ & \\
White Female & 0.725 & 0.245 & 0.241 & -0.015 & -0.010 & -0.026 & 4,526 \\
& $(0.010)$ & $(0.027)$ & $(0.028)$ & $(0.005)$ & $(0.006)$ & $(0.009)$ & \\
Black Female & 0.797 & 0.231 & 0.192 & -0.016 & -0.010 & 0.010 & 2,153 \\
& $(0.013)$ & $(0.040)$ & $(0.039)$ & $(0.008)$ & $(0.007)$ & $(0.008)$ & \\
Hispanic Female & 0.788 & 0.350 & 0.289 & -0.013 & 0.006 & -0.017 & 1,510 \\
& $(0.016)$ & $(0.047)$ & $(0.046)$ & $(0.011)$ & $(0.007)$ & $(0.008)$ & \\
\hline
\end{tabular}

Note: Each cell is taken from a different regression for the given outcome (columns) and sample group (rows). All regressions control for the economic disadvantage indicator. Regression for the full sample (first row) also controls for race-by-gender group indicators. 
Redshirting Matters

Appendix Figure C1. Rate of Delayed Grade 1 Entry, by Month of Birth

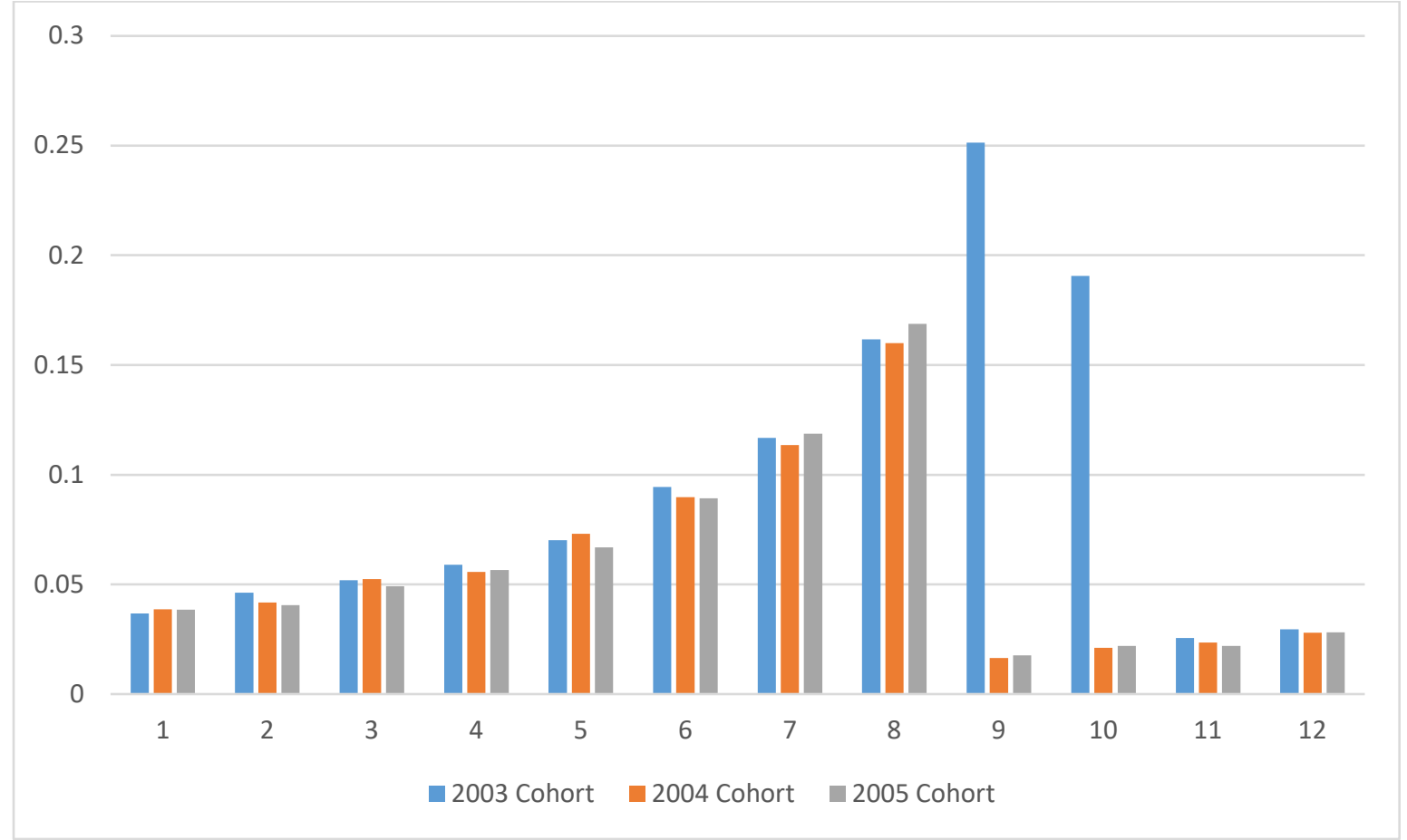

Note: Horizontal axis corresponds to calendar months. 